\title{
An Analytical Solution for Predicting Transient Seepage into Partially Penetrating Ditch Drains Receiving Water from a Ponded Field
}

\author{
Gautam BARUA and Ratan SARMAH \\ Department of Civil Engineering, Indian Institute of Technology Guwahati, \\ Guwahati, Assam, India; \\ e-mails: g_barua@iitg.ernet.in (corresponding author), ratan@iitg.ernet.in
}

\begin{abstract}
A transient analytical model is worked out for predicting seepage from a ponded field of infinite extent to a network of equally spaced ditch drains in a homogeneous and anisotropic soil underlain by an impervious barrier at a finite distance from the surface of the soil. The solution can account for finite width and finite level of water in the ditches, finite penetration of the drains in the soil, and also a variable ponding field at the surface of the soil. The study highlights the fact that the transient state duration of a partially penetrating ponded drainage scenario may be considerable should the drains be dug in a lowly conductive soil with a high storage coefficient, particularly if the underlying impervious layer lies at a large distance from the bottom of the ditches and the separation between the adjacent ditches is also large at the same time.
\end{abstract}

Key words: ponded drainage, partially penetrating drains, transient solution, hydraulic conductivity, specific storage.

\section{INTRODUCTION}

Subsurface drainage is mainly concerned with the control of waterlogging and salinity in irrigated soils for providing proper air-water ambience for the 
optimum growth of plants. Irrigation is essential for augmenting agricultural productivity in many water scarce regions of the world; it is also an important ingredient for cropping high yielding varieties since the water demand of these varieties may far exceed that of the traditional varieties (Singh and Singh 1995). Thus, irrigation forms an integral part of modern agriculture and care must be exercised to see that proper irrigation measures specific to a need be put in a cropped field. The introduction of irrigation water to the agricultural fields, however, has resulted in the twin problems of waterlogging and salinity in many areas of the world - problems which must be tackled if sustainability of irrigated agriculture is to be maintained (Ghassemi et al. 1995, FAO 2002, Rhoades 1997). The Indian irrigation scenario is not different either. It is reported that irrigation has resulted in vast areas of agricultural land of the country been affected with the problems of waterlogging and salinity to varying degrees (Datta et al. 2000, Datta and de Jong 2002, Manjunatha et al. 2004, Sharma and Gupta 2006, Ritzema et al. 2008 - to name a few).

One of the most commonly used methods of controlling salinity in a soil column is to subject the soil to a ponding head of good quality water at the surface of the soil so that the ponding head drives the water though the salt affected soil and in the process washes away a part of the salt present in the soil profile; the salt enriched water is then drained with the help of a network of subsurface drains installed in the soil (Dieleman 1973, Martinez-Beltran 1978, Rao and Leeds-Harrison 1991, Youngs and Leeds-Harrison 2000, Mirjat and Rose 2009, Barua and Alam 2013). Subsurface drainage is also now proving to be of increasing importance for draining paddy fields so as to maintain a favorable soil-water balance at the root zone of paddies (Ogino and Murashima 1993, Tabuchi 2004, Darzi-Naftchali et al. 2013) and, most importantly, for providing a check on the emission of methane from these fields, a greenhouse gas the global warming potential of which is measured only next to carbon dioxide by mass (Shiratori et al. 2007, Qiu 2009, Zhao et al. 2011, Zhang et al. 2011- to name a few). Ditch drains have been found to be particularly useful for reclaiming waterlogged and salt affected soils in areas where the conductivity of the soils is low and the topography relatively flat (Abrol et al. 1988). Ditches are distinctive ecosystems integrating both the characteristics of streams and wetlands and play important roles in controlling the hydrologic, chemical, and biological processes of a watershed (Needelman et al. 2007). Ditch drains are also reported to have a strong influence on maintaining the biodiversity of an agriculture landscape and the replacement of open ditch drains by subsurface tiles in a watershed may have a profound influence on the ecology of the watershed (Bradbury and Kirby 2006, Marja and Herzon 2012, Marja 2013). Thus, considering the importance of ditch drains for multifarious activities in an agricultural land- 
scape, it is incumbent that due emphasis be given to study in detail the hydraulics associated with a ditch drainage network so that efficient drainage networks specific to a purpose can be designed and implemented in fields.

In this study, we will be confining ourselves to study a ponded drainage system, a system which one often comes across when dealing with reclamation of waterlogged and salt affected soils and while draining paddy fields in lowland areas. Towards this end, several steady state ponded ditch drainage theories have been proposed in the past (Kirkham 1945, 1950, 1960, 1965; Kirkham et al. 1974, Fukuda 1957, Warrick and Kirkham 1969, Ilyinsky and Kacimov 1992, Youngs 1994, Barua and Tiwari 1995, Bereslavskii 2006, Römkens 2009, Chahar and Vadodaria 2008a, b; 2012) related to various aspects of the ponded ditch drainage problem. These analytical models for the different variants of the ponded ditch problem, as just mentioned, are for the steady state condition only and hence they do not reflect the transient dynamics of a ponded ditch drainage system. It is also worth noting here that a well developed ponded ditch drainage theory also provides valuable information regarding the role of subsurface seepage towards rill and gully formation in bottomland areas where ponded condition may prevail for a long period during the wet seasons; in such situations, if the groundwater meets a stream having a lower water level than the surrounding water table, considerable seepage may occur to the stream from the surroundings, leading to the possibility of incipient gully development at the banks of the stream (Römkens 2009, 2010).

Several studies (Kirkham 1950, 1960, 1965, Dieleman 1973, MartinezBeltran 1978, Rao and Leeds-Harrison 1991, Youngs 1994, Barua and Tiwari 1995, Youngs and Leeds-Harrison 2000, Mirjat and Rose 2009, Römkens 2009, Chahar and Vadodaria 2008a,b, 2012; Barua and Alam 2013 - to name only a few) related to ponded subsurface drainage using tiles or ditches clearly demonstrate the fact that the seepage velocity distribution at the surface of a uniformly ponded soil being drained by a network of tiles or ditches is pretty uneven with most of the flow occurring through areas lying close to the vicinity of the drains. Thus, leaching a contaminated soil with a uniform ponding field at the surface of the soil will lead to unequal washing of the soil profile - regions close to the drains will be over-washed and the regions away from the drains under-washed. One way of trying to achieve a relatively even leaching of a soil is by subjecting the soil to sequential ponding at the surface of the soil rather than subjecting it to full ponding all the time. Thus, full ponding of the whole soil for some time followed by ponding of half of the soil profile for more time and then finally ponding quarter of the soil profile in regions located halfway between the drains, may be adopted for having a relatively uniform leaching of a salt affected soil rather than carrying out the leaching of the whole soil all the time 
(Rao and Leeds-Harrison 1991). Another way of addressing the problem is by first ponding fraction of the area midway between the drains and then progressively increasing this area till all the region in between the drains are being covered (Youngs and Leeds-Harrison 2000, Mirjat and Rose 2009). Still another way of achieving uniformity of leaching of a salt affected soil is by subjecting it to a progressively increasing ponding distribution from the edge of the drains towards the halfway distance between two adjacent drains - that way, the entire soil profile can be leached in a single stage (Barua and Alam 2013). A noticeable aspect of this type of reclamation is that the uniformity of leaching is being attempted by just playing with the ponding distribution at the surface of the soil without the necessity of cleaning the soil in stages. The ponding distribution pertaining to a leaching scenario in context to reclamation of a salt affected soil can be worked out utilizing the mathematical works of Barua and Alam (2013) and, if this distribution is being rightly determined for the chosen scenario, considerable saving in water as well as on time of leaching may be achieved while carrying out the leaching of the salt affected soil.

It should, however, be noted that Barua and Alam's (2013) transient ditch drainage analytical model is valid only for situations where the ditches fully penetrate the soil profile and rest on the impervious layer underlying the soil column. As the ditch drains in a subsurface drainage system are hardly dug all the way up to the impervious layer in a real field setting and are thus mostly partially penetrating in nature (Szilagyi 2003), an attempt is being made here to obtain a comprehensive analytical solution to the general transient ditch drainage problem by including, apart from finite spacing between the drains and finite depth of the soil profile, partial penetration, bottom flow, and variable ponding fields as well into the infrastructure of the solution. It is hoped that the general analytical solution proposed here for the transient partially penetrating ponded ditch drainage problem would lead to better designs of ditch drainage networks for reclaiming salt affected and waterlogged soils as compared to designs based on a steady state solution or fully penetrating but transient solution of the problem. The solution presented here may be considered as an extension of Barua and Alam's (2013) solution of the transient ditch drainage problem for the fully penetrating case to that of situations where the ditches do not penetrate fully a soil profile but remain suspended at a finite height above the underlying impervious layer. This extension is being carried out here by splitting the flow domain into three sub-domains and then solving the governing equation in each of these domains, taking due care at the same time to see that all the necessary boundary and interfacial conditions applicable to each of the sub-domains are also satisfied concurrently. As an analytical model helps in understanding the conceptual behavior associated with a groundwater system, it is 
hoped that the solution presented here would lead to having a better insight on the transient hydraulics of flow associated with a partially penetrating ditch drainage system receiving water from a uniform or a variably ponded field. Further, as an analytical model is also frequently been used to test the accuracy of complex numerical codes pertaining to a groundwater system after first reducing it to the relatively simpler conditions for which the analytical model is being developed (Elfeki et al. 1997, Kacimov 1997, Haitjema 2006, Praveena et al. 2010), it is also hoped that the model proposed here would prove to be useful in checking the validity of complex numerical solutions related to subsurface drainage which can be reduced to the comparatively simple solution that has been obtained in the current study.

\section{MATHEMATICAL FORMULATION AND SOLUTION}

Figure 1 shows the geometry of the flow problem under consideration. An array of equally spaced partially penetrating ditch drains are draining a homogeneous and anisotropic soil underlain by an impervious layer, the soil being subjected to a variable ponding field, as can be seen in the figure. We take the origin $O$ on the vertical line passing through the centre of a ditch and measure the $x$-axis to be positive towards the right of the origin and the $y$-axis to be positive vertically downward of the origin. The semi-spacing between the drains (as measured from the edge of the drains) is taken as $S$ and the width of the drains as $a$. The thickness of the soil column is considered as $h$, and $H_{1}$ and $H_{3}$ denote the water level depth and depth of penetration of the drains, respectively, all these distances being measured with respect to the origin $O$. The directional conductivities of the soil in the horizontal and vertical directions are taken as $K_{x}$ and $K_{y}$, respectively, and $S_{s}$ is the specific storage of the soil. The symmetrical ponding distribution at the surface of the soil with respect to the groundwater divide line passing though halfway between the drains is being imposed in between two adjacent drains with the help of $2 N_{0}-2\left(N_{0}>1\right)$ number of inner bunds with $\delta_{j}\left(\delta_{j}=\delta_{2 N_{0}-j}\right)$ $\left(1 \leq j \leq 2 N_{0}-1\right)$ representing the ponding depth corresponding to the $j$ th ponded subspace.

The inner bunds are all assumed to be impervious and of infinitesimal thickness and the distance of the $j$ th inner bund from the edge of the left ditch is taken as $S_{j}\left(1 \leq j \leq 2 N_{0}-2\right)$. The ponded water at the surface of the soil is being prevented from directly flowing to a ditch with the help of two impervious ditch banks of infinitesimal width $\varepsilon$ placed on either side of the ditch. In our analysis, we assume the soil to be fully saturated and the ponding depth(s) and the height of water in the ditches to be non- changing with time. Further, we also assume that the imposition of the ponding field at the 


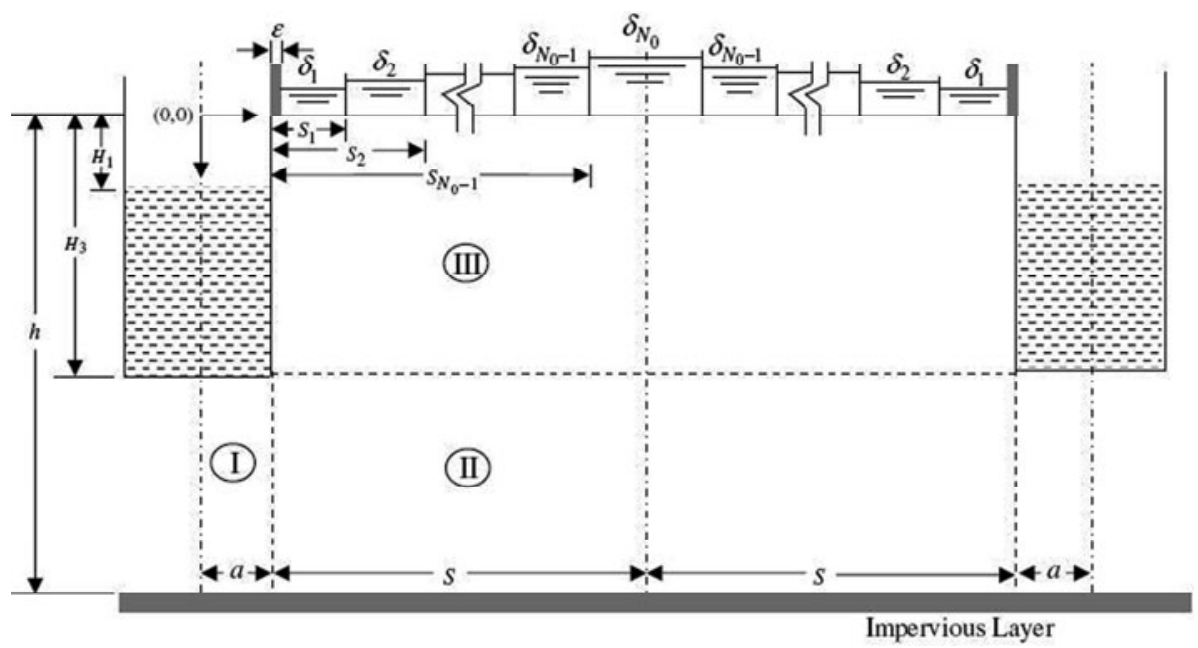

Fig. 1. Geometry of a partially penetrating ditch drainage system in a homogeneous and anisotropic soil subjected to a variable depth of ponding at the surface of the soil.

surface of the soil and the lowering of water level in the ditches have been done instantaneously, the soil being previously assumed to be saturated all the way up to the surface of the soil with the level of water in the drains flush with the horizontal soil surface. As the flow is symmetrical with respect to the groundwater divide line passing through midway between the drains, we consider only half of the flow space for analysis as the flow in one half will be the mirror image of the other half. Further, for mathematical convenience, we perform a domain discretization of the flow domain of a nature as shown in Fig. 1 and name the hydraulic heads in these regions as $\varphi_{1}$, $\varphi_{2}$, and $\varphi_{3}$, respectively.

With the above definitions of the symbols and also calling the time variable as $t$, we now sought to obtain an analytical solution to the two-dimensional transient groundwater flow equation for a homogeneous, anisotropic and compressible soil

$$
K_{x} \frac{\partial^{2} \varphi_{i}}{\partial x^{2}}+K_{y} \frac{\partial^{2} \varphi_{i}}{\partial y^{2}}=S_{s}\left(\frac{\partial \varphi_{i}}{\partial t}\right), \quad(i=1,2,3),
$$

subject to the following initial, boundary and interfacial conditions

$$
\begin{array}{lll}
\varphi_{1}(x, y, t=0)=0, & 0<x<a, & H_{3}<y<h, \\
\frac{\partial \varphi_{1}(x, y, t>0)}{\partial x}=0, & x=0, & H_{3}<y<h,
\end{array}
$$




$$
\begin{aligned}
& \varphi_{1}(x, y, t>0)=-H_{1}, \quad 0<x<a, \quad y=H_{3}, \\
& \varphi_{1}(x, y, t>0)=\varphi_{2}(x, y, t>0), \quad x=a, \quad H_{3}<y<h, \\
& \frac{\partial \varphi_{1}(x, y, t>0)}{\partial x}=\frac{\partial \varphi_{2}(x, y, t>0)}{\partial x}, \quad x=a, \quad H_{3}<y<h, \\
& \frac{\partial \varphi_{1}(x, y, t>0)}{\partial y}=0, \quad 0<x<a, \quad y=h, \\
& \varphi_{2}(x, y, t=0)=0, \quad a<x<S+a, \quad H_{3}<y<h, \\
& \frac{\partial \varphi_{2}(x, y, t>0)}{\partial x}=0, \quad x=S+a, \quad H_{3}<y<h, \\
& \frac{\partial \varphi_{2}(x, y, t>0)}{\partial y}=0, \quad a<x<S+a, \quad y=h, \\
& \varphi_{2}(x, y, t>0)=\varphi_{3}(x, y, t>0), \quad a<x<S+a, \quad y=H_{3}, \\
& \frac{\partial \varphi_{2}(x, y, t>0)}{\partial y}=\frac{\partial \varphi_{3}(x, y, t>0)}{\partial y}, \quad a<x<S+a, \quad y=H_{3}, \\
& \varphi_{3}(x, y, t=0)=0, \quad a<x<S+a, \quad 0<y<H_{3}, \\
& \varphi_{3}(x, y, t>0)=-y, \quad x=a, \quad 0<y \leq H_{1}, \\
& \varphi_{3}(x, y, t>0)=-H_{1}, \quad x=a, \quad H_{1}<y<H_{3}, \\
& \frac{\partial \varphi_{3}(x, y, t>0)}{\partial x}=0, \quad x=S+a, \quad 0<y<H_{3}, \\
& \varphi_{3}(x, y, t>0)=\delta_{1}, \quad a<x<S_{1}+a, \quad y=0, \\
& \varphi_{3}(x, y, t>0)=\delta_{j}, \quad S_{j-1}+a<x<S_{j}+a, \quad y=0,\left(2 \leq j \leq N_{0}-1\right)
\end{aligned}
$$

(condition XVII will be applicable only for situations where $N_{0} \geq 3$ )

$$
\varphi_{3}(x, y, t>0)=\delta_{N_{0}}, \quad S_{N_{0}-1}+a<x<S+a, \quad y=0 .
$$

To make it easier to obtain the solution to the problem, we now first carry out a horizontal transformation

$$
X=\left(\sqrt{\frac{K_{y}}{K_{x}}}\right) x=\frac{x}{K^{a}},
$$

on Eq. 1; this reduces Eq. 1 to 


$$
\frac{\partial^{2} \varphi_{i}}{\partial X^{2}}+\frac{\partial^{2} \varphi_{i}}{\partial y^{2}}=\left(K_{1}\right)^{2}\left(\frac{\partial \varphi_{i}}{\partial t}\right)
$$

where

$$
\left(K_{1}\right)^{2}=\left(\frac{S_{s}}{K_{y}}\right)
$$

and

$$
K^{a}=\left(\sqrt{\frac{K_{x}}{K_{y}}}\right) .
$$

Taking in view the nature of the initial, boundary, and interfacial conditions of the problem, the hydraulic head functions corresponding to the three regions of the considered flow space, utilizing the separation of variable method (Kirkham and Powers 1972), can be expressed as

$$
\begin{aligned}
& \varphi_{1}(X, y, t)=\sum_{w=1}^{W} F_{w} \frac{\cosh \left(N_{w} X\right)}{\cosh \left(N_{w} a_{X}\right)} \sin \left[N_{w}\left(y-H_{3}\right)\right] \\
& +\sum_{m_{1}=1}^{M_{1}} \sum_{n_{1}=1}^{N_{1}} Z_{m_{1} n_{1}} \sin \left[N_{m_{1}}\left(y-H_{3}\right)\right] \cos \left(N_{n_{1}} X\right) \exp \left[-\frac{\left(\lambda_{m_{1} n_{1}}\right)^{2} t}{\left(K_{1}\right)^{2}}\right]-H_{1} \text {, } \\
& \left(0<X<a_{X}, H_{3}<y<h\right) \text {, } \\
& \varphi_{2}(X, y, t)=\sum_{r=1}^{R} D_{r} \frac{\cosh \left[N_{r}\left(S_{X}+a_{X}-X\right)\right]}{\cosh \left(N_{r} S_{X}\right)} \sin \left[N_{r}\left(y-H_{3}\right)\right] \\
& +\sum_{n=1}^{N} E_{n} \frac{\cosh \left[N_{n}(h-y)\right]}{\sinh \left[N_{n}\left(h-H_{3}\right)\right]} \sin \left[N_{n}\left(X-a_{X}\right)\right] \\
& +\sum_{m_{1}=1}^{M_{1}} \sum_{n_{1}=1}^{N_{1}} Z_{m_{1} n_{1}} \sin \left[N_{m_{1}}\left(y-H_{3}\right)\right] \cos \left(N_{n_{1}} X\right) \exp \left[-\frac{\left(\lambda_{m_{1} n_{1}}\right)^{2} t}{\left(K_{1}\right)^{2}}\right] \\
& +\sum_{m_{2}=1}^{M_{2}} \sum_{n_{2}=1}^{N_{2}} A_{m_{2} n_{2}} \sin \left(N_{m_{2}} y\right) \sin \left[N_{n_{2}}\left(X-a_{X}\right)\right] \exp \left[-\frac{\left(\lambda_{m_{2} n_{2}}\right)^{2} t}{\left(K_{1}\right)^{2}}\right]-H_{1}, \\
& \left(a_{X}<X<S_{X}+a_{X}, H_{3}<y<h\right)
\end{aligned}
$$

and 


$$
\begin{aligned}
\varphi_{3}(X, y, t)= & \sum_{q=1}^{Q} C_{q} \frac{\cosh \left[N_{q}\left(S_{X}+a_{X}-X\right)\right]}{\cosh \left(N_{q} S_{X}\right)} \sin \left(N_{q} y\right) \\
& +\sum_{p=1}^{P} B_{p} \frac{\sinh \left(N_{p} y\right)}{\cosh \left(N_{p} H_{3}\right)} \sin \left[N_{p}\left(X-a_{X}\right)\right] \\
& +\sum_{m=1}^{M} G_{m} \frac{\sinh \left[N_{m}\left(H_{3}-y\right)\right]}{\sinh \left(N_{m} H_{3}\right)} \sin \left[N_{m}\left(X-a_{X}\right)\right] \\
& +\sum_{m_{2}=1}^{M_{2}} \sum_{n_{2}=1}^{N_{2}} A_{m_{2} n_{2}} \sin \left(N_{m_{2}} y\right) \sin \left[N_{n_{2}}\left(X-a_{X}\right)\right] \exp \left[\begin{array}{c}
\left(\lambda_{m_{2} n_{2}}\right)^{2} t \\
\left(K_{1}\right)^{2}
\end{array}\right], \\
& \quad\left(a_{X}<X<S_{X}+a_{X}, \quad 0<y<H_{3}\right),
\end{aligned}
$$

where

$$
\begin{gathered}
N_{w}=\left[\left(\frac{1-2 w}{2}\right) \frac{\pi}{h-H_{3}}\right], \\
N_{r}=\left[\left(\frac{1-2 r}{2}\right) \frac{\pi}{h-H_{3}}\right], \\
N_{n}=\left[\left(\frac{1-2 n}{2}\right) \frac{\pi}{S_{X}}\right], \\
N_{q}=\left[\left(\frac{1-2 q}{2}\right) \frac{\pi}{H_{3}}\right], \\
N_{p}=\left[\left(\frac{1-2 p}{2}\right) \frac{\pi}{S_{X}}\right], \\
N_{m}=\left[\left(\frac{1-2 m}{2}\right) \frac{\pi}{S_{X}}\right], \\
N_{m_{1}}=\left[\left(\frac{1-2 m_{1}}{2}\right) \frac{\pi}{h-H_{3}}\right], \\
N_{n_{1}} \\
=\left[\frac{n_{1} \pi}{S_{X}+a_{X}}\right],
\end{gathered}
$$




$$
\begin{gathered}
N_{m_{2}}=\left[\left(\frac{1-2 m_{2}}{2}\right) \frac{\pi}{h}\right], \\
N_{n_{2}}=\left[\left(\frac{1-2 n_{2}}{2}\right) \frac{\pi}{S_{X}}\right], \\
\lambda_{m_{1} n_{1}}^{2}=N_{m_{1}}^{2}+N_{n_{1}}^{2}, \\
\lambda_{m_{2} n_{2}}^{2}=N_{m_{2}}^{2}+N_{n_{2}}^{2}, \\
a_{X}=\left(\sqrt{\frac{K_{y}}{K_{x}}}\right) a, \\
S_{X}=\left(\sqrt{\frac{K_{y}}{K_{x}}}\right) S
\end{gathered}
$$

and $F_{w}, D_{r}, E_{n}, C_{q}, B_{p}, G_{m}, Z_{m_{1} n_{1}}$, and $A_{m_{2} n_{2}}$ are constants to be determined utilizing the boundary and interfacial conditions as given above.

We first obtain a steady state solution to the problem by letting $t \rightarrow \infty$ in the expressions for the hydraulic head functions. This would naturally make the exponential terms in these equations to disappear leaving only the steady state terms to deal with. Once the steady state solution is obtained, it can then be used in solving the considered flow problem for the transient situation. The detailed process of determining the coefficients of $\varphi_{1}, \varphi_{2}$, and $\varphi_{3}$ utilizing the conditions I to XVIII as listed above is described in the Appendix. As shown in the Appendix, the expressions for estimating $C_{q}$ and $G_{m}$ are as given by Eqs. A4 and A10, respectively, and the expressions for generating the necessary set of linear equations for estimating $F_{w}, D_{r}, E_{n}$, and $B_{p}$ are as given by Eqs. A12, A17, A23, and A30, respectively. Further, once these coefficients corresponding to a flow situation are determined, Eqs. A73 and A99 can then be utilized to generate the requisite linear equations for estimating the coefficients $Z_{m_{1} n_{1}}$ and $A_{m_{2} n_{2}}$; the detailed process for the same is explained in the Appendix. It is worth mentioning at this stage that the summation of our single summation series up to 10 to 15 terms, (i.e., $P=$ $Q=R=M=N=W=10$ to 15$)$ and that of the double summation series up to 10 to 12 terms (i.e., $M_{1}=N_{1}=M_{2}=N_{2}=10$ to 12 ) have been found sufficient for achieving convergence of our series solution to a high level of accuracy for all the drainage examples considered in the manuscript.

The horizontal and vertical velocity distribution functions, $V_{x i}$ and $V_{y i}$, for the flow domain 1, 2, and 3 of Fig. 1 in the real space can be determined 
by applying the Darcy's law to the relevant hydraulic head functions related to these domains; thus we have

$$
V_{x i}(x, y, t)=-K_{x} \frac{\partial \varphi_{i}(x, y, t)}{\partial x}
$$

and

$$
V_{y i}(x, y, t)=-K_{y} \frac{\partial \varphi_{i}(x, y, t)}{\partial y}, \quad(i=1,2,3) .
$$

Carrying out the above differentiations after first converting the hydraulic head functions to the real space using the relations given by Eq. 2, $8 \mathrm{~m}$ and $8 \mathrm{n}$, we get

$$
\begin{aligned}
& V_{x 1}(x, y, t)=-K_{x}\left\{\sum_{w=1}^{W} F_{w}\left(\frac{N_{w}}{K^{a}}\right) \frac{\sinh \left(\frac{N_{w} x}{K^{a}}\right)}{\cosh \left(\frac{N_{w} a}{K^{a}}\right)} \sin \left[N_{w}\left(y-H_{3}\right)\right]\right. \\
&\left.-\sum_{m_{1}=1}^{M_{1}} \sum_{n_{1}=1}^{N_{1}} Z_{m_{1} n_{1}}\left(\frac{N_{n_{1}}}{K^{a}}\right) \sin \left[N_{m_{1}}\left(y-H_{3}\right)\right] \sin \left(\frac{N_{n_{1}} x}{K^{a}}\right) \exp \left[-\frac{\left(\lambda_{m_{1} n_{1}}\right)^{2} t}{\left(K_{1}\right)^{2}}\right]\right\}, \\
& V_{x 2}(x, y, t)=-K_{x}\left\{-\sum_{r=1}^{R} D_{r}\left(\frac{N_{r}}{K^{a}}\right) \frac{\sinh \left[\frac{N_{r}(S+a-x)}{K^{a}}\right]}{\cosh \left(\frac{N_{r} S}{K^{a}}\right)} \sin \left[H_{r}<y<h\right),\right. \\
&+\sum_{n=1}^{N} E_{n}\left(\frac{N_{n}}{K^{a}}\right) \frac{\cosh \left[N_{n}(h-y)\right]}{\left.\sinh \left[H_{3}\right)\right]} \cos \left[\frac{N_{n}(x-a)}{K^{a}}\right] \\
&\left.-\sum_{m_{1}=1}^{M_{1}} \sum_{n_{1}=1}^{N_{1}} Z_{m_{1} n_{1}}\left(\frac{N_{n_{1}}}{K^{a}}\right) \sin \left[H_{3}\right)\right] \\
&\left.\left.+\sum_{m_{2}=1}^{M_{2}} \sum_{n_{2}=1}^{N_{2}} A_{m_{2} n_{2}}\left(\frac{N_{n_{2}}}{K^{a}}\right) \sin \left(H_{3}\right)\right] \sin \left(\frac{N_{n_{1}} x}{K^{a}}\right) \exp \left[-\frac{\left(\lambda_{m_{1} n_{1}}\right)^{2} t}{\left(K_{1}\right)^{2}}\right] \cos \left[\frac{N_{n_{2}}(x-a)}{K^{a}}\right] \exp \left[-\frac{\left(\lambda_{m_{2} n_{2}}\right)^{2} t}{\left(K_{1}\right)^{2}}\right]\right\} \\
&\left(a<x<S+a, H_{3}<y<h\right),
\end{aligned}
$$




$$
\begin{aligned}
& V_{x 3}(x, y, t)=-K_{x}\left\{-\sum_{q=1}^{Q} C_{q}\left(\frac{N_{q}}{K^{a}}\right) \frac{\sinh \left[\frac{N_{q}(S+a-x)}{K^{a}}\right]}{\cosh \left(\frac{N_{q} S}{K^{a}}\right)} \sin \left(N_{q} y\right)\right. \\
&+\sum_{p=1}^{P} B_{p}\left(\frac{N_{p}}{K^{a}}\right) \frac{\sinh \left(N_{p} y\right)}{\cosh \left(N_{p} H_{3}\right)} \cos \left[\frac{N_{p}(x-a)}{K^{a}}\right] \\
&+\sum_{m=1}^{M} G_{m}\left(\frac{N_{m}}{K^{a}}\right) \frac{\sinh \left[N_{m}\left(H_{3}-y\right)\right]}{\sinh \left(N_{m} H_{3}\right)} \cos \left[\frac{N_{m}(x-a)}{K^{a}}\right] \\
&\left.+\sum_{m_{2}=1}^{M_{2}} \sum_{n_{2}=1}^{N_{2}} A_{m_{2} n_{2}}\left(\frac{N_{n_{2}}}{K^{a}}\right) \sin \left(N_{m_{2}} y\right) \cos \left[\frac{N_{n_{2}}(x-a)}{K^{a}}\right] \exp \left[-\frac{\left(\lambda_{m_{2} n_{2}}\right)^{2} t}{\left(K_{1}\right)^{2}}\right]\right\}, \\
& \quad\left(a<x<S+a, 0<y<H_{3}\right)^{2},
\end{aligned}
$$

$$
\begin{aligned}
V_{y 1}(x, y, t)= & -K_{y}\left\{\sum_{w=1}^{W} F_{w} N_{w} \frac{\cosh \left(\frac{N_{w} x}{K^{a}}\right)}{\cosh \left(\frac{N_{w} a}{K^{a}}\right)} \cos \left[N_{w}\left(y-H_{3}\right)\right]\right. \\
+ & \left.\sum_{m_{1}=1}^{M_{1}} \sum_{n_{1}=1}^{N_{1}} Z_{m_{1} n_{1}} N_{m_{1}} \cos \left[N_{m_{1}}\left(y-H_{3}\right)\right] \cos \left(\frac{N_{n_{1}} x}{K^{a}}\right) \exp \left[-\frac{\left(\lambda_{m_{1} n_{1}}\right)^{2} t}{\left(K_{1}\right)^{2}}\right]\right\}, \\
& \left(0<x<a, H_{3}<y<h\right),
\end{aligned}
$$

$$
\begin{aligned}
& V_{y 2}(x, y, t)=-K_{y}\left\{\sum_{r=1}^{R} D_{r} N_{r} \frac{\cosh \left[\frac{N_{r}(S+a-x)}{K^{a}}\right]}{\cosh \left(\frac{N_{r} S}{K^{a}}\right)} \cos \left[N_{r}\left(y-H_{3}\right)\right]\right. \\
&-\sum_{n=1}^{N} E_{n} N_{n} \frac{\sinh \left[N_{n}(h-y)\right]}{\sinh \left[N_{n}\left(h-H_{3}\right)\right]} \sin \left[\frac{N_{n}(x-a)}{K^{a}}\right] \\
&+\sum_{m_{1}=1}^{M_{1}} \sum_{n_{1}=1}^{N_{1}} Z_{m_{1} n_{1}} N_{m_{1}} \cos \left[N_{m_{1}}\left(y-H_{3}\right)\right] \cos \left(\frac{N_{n_{1}} x}{K^{a}}\right) \exp \left[-\frac{\left(\lambda_{m_{1} n_{1}}\right)^{2} t}{\left(K_{1}\right)^{2}}\right] \\
&\left.+\sum_{m_{2}=1}^{M_{2}} \sum_{n_{2}=1}^{N_{2}} A_{m_{2} n_{2}} N_{m_{2}} \cos \left(N_{m_{2}} y\right) \sin \left[\frac{N_{n_{2}}(x-a)}{K^{a}}\right] \exp \left[-\frac{\left(\lambda_{m_{2} n_{2}}\right)^{2} t}{\left(K_{1}\right)^{2}}\right]\right\}, \\
&\left(a<x<S+a, H_{3}<y<h\right)
\end{aligned}
$$


and

$$
\begin{aligned}
& V_{y 3}(x, y, t)=-K_{y}\left\{\sum_{q=1}^{Q} C_{q} N_{q} \frac{\cosh \left[\frac{N_{q}(S+a-x)}{K^{a}}\right]}{\cosh \left(\frac{N_{q} S}{K^{a}}\right)} \cos \left(N_{q} y\right)\right. \\
&+\sum_{p=1}^{P} B_{p} N_{p} \frac{\cosh \left(N_{p} y\right)}{\cosh \left(N_{p} H_{3}\right)} \sin \left[\frac{N_{p}(x-a)}{K^{a}}\right] \\
&-\sum_{m=1}^{M} G_{m} N_{m} \frac{\cosh \left[N_{m}\left(H_{3}-y\right)\right]}{\sinh \left(N_{m} H_{3}\right)} \sin \left[\frac{N_{m}(x-a)}{K^{a}}\right] \\
&\left.+\sum_{m_{2}=1}^{M_{2}} \sum_{n_{2}=1}^{N_{2}} A_{m_{2} n_{2}} N_{m_{2}} \cos \left(N_{m_{2}} y\right) \sin \left[\frac{N_{n_{2}}(x-a)}{K^{a}}\right] \exp \left[-\frac{\left(\lambda_{m_{2} n_{2}}\right)^{2} t}{\left(K_{1}\right)^{2}}\right]\right\}, \\
& \quad\left(a<x<S+a, 0<y<H_{3}\right) .
\end{aligned}
$$

To determine the transient discharge function at the top of the soil, we apply the Darcy's law at the surface of the soil using the hydraulic head function (Eq. 7) of domain 3; thus, we have

$$
Q_{\mathrm{top}}(t) / 2=-\left(\sqrt{K_{x} K_{y}}\right) \int_{a_{X}+\varepsilon_{X}}^{S_{X}+a_{X}}\left[\frac{\partial \varphi_{3}(X, y, t)}{\partial y}\right]_{y=0} d X,
$$

where $Q_{\text {top }}$ is the discharge rate at the surface of the soil per unit length of the ditches and

$$
\varepsilon_{X}=\left(\sqrt{\frac{K_{y}}{K_{x}}}\right) \varepsilon .
$$

Evaluation of the integral of Eq. 17, using Eq. 7, yields

$$
\begin{aligned}
Q_{\text {top }}(t) / 2= & -\left(\sqrt{K_{x} K_{y}}\right)\left\{\sum_{q=1}^{Q} C_{q} \frac{\sinh \left[N_{q}\left(S_{X}-\varepsilon_{X}\right)\right]}{\cosh \left(N_{q} S_{X}\right)}+\sum_{p=1}^{P} B_{p} \frac{\cos \left(N_{p} \varepsilon_{X}\right)}{\cosh \left(N_{p} H_{3}\right)}\right. \\
& -\sum_{m=1}^{M} G_{m} \operatorname{coth}\left(N_{m} H_{3}\right) \cos \left(N_{m} \varepsilon_{X}\right) \\
& \left.+\sum_{m_{2}=1}^{M_{2}} \sum_{n_{2}=1}^{N_{2}} A_{m_{2} n_{2}}\left(\frac{N_{m_{2}}}{N_{n_{2}}}\right) \cos \left(N_{n_{2}} \varepsilon_{X}\right) \exp \left[-\frac{\left(\lambda_{m_{2} n_{2}}\right)^{2} t}{\left(K_{1}\right)^{2}}\right]\right\} .
\end{aligned}
$$


We now show that $Q_{\text {top }}$ diverges if the depth of ponding in the first strip, $\delta_{1}$, is non-zero and at the same time the width of the ditch bunds $\varepsilon_{X}$ is zero. To do that, we substitute $G_{m}$ of Eq. A10 in Eq. 19; this will result, after some simplifications, in an expression having a series of the type $\sum_{m=1}^{M \rightarrow \infty}\left(2 \delta_{1} / S_{X} N_{m}\right) \operatorname{coth}\left(N_{m} H_{3}\right)$. Remembering $N_{m}=(1-2 m) \pi /\left(2 S_{X}\right)$ and noting that $\operatorname{coth}\left(N_{m} H_{3}\right)$ tends to -1 when $m$ is allowed to increase incessantly, i.e.,

$$
\operatorname{Lim}_{\mathrm{m} \rightarrow \infty}\left[\operatorname{coth}\left(N_{m} H_{3}\right)\right]=\operatorname{Lim}_{\mathrm{m} \rightarrow \infty}\left\{\operatorname{coth}\left[\frac{(1-2 m) \pi}{2 S_{X}} H_{3}\right]\right\}=-1,
$$

we see that the series

$$
\sum_{m=1}^{M \rightarrow \infty} \frac{2 \delta_{1}}{S_{X} N_{m}} \operatorname{coth}\left[\frac{(1-2 m) \pi}{2 S_{X}} H_{3}\right]=\sum_{m=1}^{M \rightarrow \infty} \frac{4 \delta_{1}}{(1-2 m) \pi} \operatorname{coth}\left[\frac{(1-2 m) \pi}{2 S_{X}} H_{3}\right]
$$

reduces to $\left(\frac{4 \delta_{1}}{\pi}\right)\left(\frac{1}{7}+\frac{1}{9}+\frac{1}{11}+\ldots ..\right)$ if $\operatorname{coth}\left(N_{m} H_{3}\right)$ is assumed to reach somewhere very close to -1 after carrying out the summation of the first three terms of the series. This infinite series, however, is a diverging series, and thus $Q_{\text {top }}$ diverges if $\delta_{1} \neq 0$ and $\varepsilon_{X}=0$.

Now, to estimate the discharge per unit length through the sides of a ditch, $Q_{\text {side }}(t)$, for situations where $\delta_{1}=0$ and $\varepsilon_{X}=0$, we apply the Darcy's law at the sides, namely

$$
Q_{\text {side }}(t) / 2=\left(\sqrt{K_{x} K_{y}}\right) \int_{0}^{H_{3}}\left[\frac{\partial \varphi_{3}(X, y, t)}{\partial X}\right]_{X=a_{X}} d y .
$$

Simplification of the above integral, using Eq. 7, gives

$$
\begin{aligned}
& Q_{\text {side }}(t) / 2=\left(\sqrt{K_{x} K_{y}}\right)\left\{\left[-\sum_{q=1}^{Q} C_{q} \tanh \left(N_{q} S_{X}\right)+\sum_{p=1}^{P} B_{p}\left[\frac{\cosh \left(N_{p} H_{3}\right)-1}{\cosh \left(N_{p} H_{3}\right)}\right]\right.\right. \\
& \left.+\sum_{m=1}^{M} G_{m}\left[\frac{\cosh \left(N_{m} H_{3}\right)-1}{\sinh \left(N_{m} H_{3}\right)}\right]+\sum_{m_{2}=1}^{M_{2}} \sum_{n_{2}=1}^{N_{2}} A_{m_{2} n_{2}}\left(\frac{N_{n_{2}}}{N_{m_{2}}}\right)\left[1-\cos \left(N_{m_{2}} H_{3}\right)\right] \exp \left[-\frac{\left(\lambda_{m_{2} n_{2}}\right)^{2} t}{\left(K_{1}\right)^{2}}\right]\right\} .
\end{aligned}
$$

In the same way, the discharge through the bottom of a ditch per unit length, $Q_{\text {bottom }}(t)$, can also be determined by making use of the Darcy's law at the bottom face of a ditch; thus, we have 


$$
Q_{\text {bottom }}(t) / 2=\left(\sqrt{K_{x} K_{y}}\right) \int_{0}^{a_{X}}\left[\frac{\partial \varphi_{1}(X, y, t)}{\partial y}\right]_{y=H_{3}} d X .
$$

Simplification of the above integral, using Eq. 5, leads to

$$
\begin{aligned}
Q_{\text {bottom }}(t) / 2= & \left(\sqrt{K_{x} K_{y}}\right)\left\{\sum_{w=1}^{W} F_{w} \tanh \left(N_{w} a_{X}\right)\right. \\
& \left.+\sum_{m_{1}=1}^{M_{1}} \sum_{n_{1}=1}^{N_{1}} Z_{m_{1} n_{1}}\left(\frac{N_{m_{1}}}{N_{n_{1}}}\right) \sin \left(N_{n_{1}} a_{X}\right) \exp \left[-\frac{\left(\lambda_{m_{1} n_{1}}\right)^{2} t}{\left(K_{1}\right)^{2}}\right]\right\} .
\end{aligned}
$$

We would like to point out here that all the expressions related to the hydraulic heads and discharge functions will reduce to the steady state situation when the time variable $t$ in them is given a very large value (theoretically infinite); as may be noted, letting $t \rightarrow \infty$ in these expressions makes the exponential terms in these equations to disappear, leaving only the steady state terms behind.

Now, the volume of water seeping through the surface of the soil in time $T$ can be expressed by integrating Eq. 19; thus, we have

$$
\mathrm{Vol}_{\text {top }} / 2=\int_{0}^{T} Q_{\text {top }}(t) / 2 d t,
$$

Evaluation of the above integral gives

$$
\begin{aligned}
\mathrm{Vol}_{\text {top }} / 2= & -\left(\sqrt{K_{x} K_{y}}\right)\left\{\sum_{q=1}^{Q}\left[C_{q} \frac{\sinh \left[N_{q}\left(S_{X}-\varepsilon_{X}\right)\right]}{\cosh \left(N_{q} S_{X}\right)}\right] \times T\right. \\
& +\sum_{p=1}^{P}\left[B_{p} \frac{\cos \left(N_{p} \varepsilon_{X}\right)}{\cosh \left(N_{p} H_{3}\right)}\right] \times T-\sum_{m=1}^{M}\left[G_{m} \operatorname{coth}\left(N_{m} H_{3}\right) \cos \left(N_{m} \varepsilon_{X}\right)\right] \times T \\
& \left.+\sum_{m_{2}=1}^{M_{2}} \sum_{n_{2}=1}^{N_{2}} A_{m_{2} n_{2}}\left(\frac{N_{m_{2}}}{N_{n_{2}}}\right) \cos \left(N_{n_{2}} \varepsilon_{X}\right) \frac{\left(K_{1}\right)^{2}}{\left(\lambda_{m_{2} n_{2}}\right)^{2}}\left[1-\exp \left[-\frac{\left(\lambda_{m_{2} n_{2}}\right)^{2} T}{\left(K_{1}\right)^{2}}\right]\right]\right\} .
\end{aligned}
$$

Similarly, expressions for the volume of water seeping though the sides and bottom of a ditch can be represented as

$$
\mathrm{Vol}_{\text {side }} / 2=\int_{0}^{T} Q_{\text {side }}(t) / 2 d t
$$

and

$$
\mathrm{Vol}_{\text {bottom }} / 2=\int_{0}^{T} Q_{\text {bottom }}(t) / 2 d t
$$


Simplifying the above integrals using Eqs. 21 and 23, respectively, we get

$$
\begin{aligned}
\mathrm{Vol}_{\text {side }} / 2= & \left(\sqrt{K_{x} K_{y}}\right)\left\{-\sum_{q=1}^{Q}\left[C_{q} \tanh \left(N_{q} S_{X}\right)\right] \times T\right. \\
& +\sum_{p=1}^{P}\left[B_{p}\left[\frac{\cosh \left(N_{p} H_{3}\right)-1}{\cosh \left(N_{p} H_{3}\right)}\right]\right] \times T+\sum_{m=1}^{M}\left[G_{m}\left[\frac{\cosh \left(N_{m} H_{3}\right)-1}{\sinh \left(N_{m} H_{3}\right)}\right]\right] \times T \\
& \left.+\sum_{m_{2}=1}^{M_{2}} \sum_{n_{2}=1}^{N_{2}} A_{m_{2} n_{2}}\left(\frac{N_{n_{2}}}{N_{m_{2}}}\right) \frac{\left(K_{1}\right)^{2}}{\left(\lambda_{m_{2} n_{2}}\right)^{2}}\left[1-\cos \left(N_{m_{2}} H_{3}\right)\right]\left[1-\exp \left[-\frac{\left(\lambda_{m_{2} n_{2}}\right)^{2} T}{\left(K_{1}\right)^{2}}\right]\right]\right\}
\end{aligned}
$$

and

$$
\begin{aligned}
\operatorname{Vol}_{\text {bottom }} / 2= & \left(\sqrt{K_{x} K_{y}}\right)\left\{\sum_{w=1}^{W}\left[F_{w} \tanh \left(N_{w} a_{X}\right)\right] \times T\right. \\
& \left.+\sum_{m_{1}=1}^{M_{1}} \sum_{n_{1}=1}^{N_{1}} Z_{m_{1} n_{1}}\left(\frac{N_{m_{1}}}{N_{n_{1}}}\right) \frac{\left(K_{1}\right)^{2}}{\left(\lambda_{m_{1} n_{1}}\right)^{2}} \sin \left(N_{n_{1}} a_{X}\right)\left[1-\exp \left[-\frac{\left(\lambda_{m_{1} n_{1}}\right)^{2} T}{\left(K_{1}\right)^{2}}\right]\right]\right\} .
\end{aligned}
$$

Now, expressions for the steady state stream functions $\psi_{1}, \psi_{2}$, and $\psi_{3}$ corresponding to the three domains of Fig. 1 can be evaluated by making use of the following relations (Bear 1972)

$$
K \frac{\partial \varphi_{i}}{\partial X}=\frac{\partial \psi_{i}}{\partial y}
$$

and

$$
K \frac{\partial \varphi_{i}}{\partial y}=-\frac{\partial \psi_{i}}{\partial X}, \quad(i=1,2,3),
$$

where $K$ is the hydraulic conductivity of an isotropic soil. We have here, in the computational domain, $K=\sqrt{K_{x} K_{y}}$; thus, applying Eqs. 30 and 31 to Eqs. 5-7, respectively, for the steady state situation, we get

$$
\begin{aligned}
\psi_{1}(X, y)= & -\left(\sqrt{K_{x} K_{y}}\right) \sum_{w=1}^{W} F_{w} \frac{\sinh \left(N_{w} X\right)}{\cosh \left(N_{w} a_{X}\right)} \cos \left[N_{w}\left(y-H_{3}\right)\right], \\
\psi_{2}(X, y)= & \left(\sqrt{K_{x} K_{y}}\right)\left\{\sum_{r=1}^{R} D_{r} \frac{\sinh \left[N_{r}\left(S_{X}+a_{X}-X\right)\right]}{\cosh \left(N_{r} S_{X}\right)} \cos \left[N_{r}\left(y-H_{3}\right)\right]\right. \\
& \left.-\sum_{n=1}^{N} E_{n} \frac{\sinh \left[N_{n}(h-y)\right]}{\sinh \left[N_{n}\left(h-H_{3}\right)\right]} \cos \left[N_{n}\left(X-a_{X}\right)\right]\right\}
\end{aligned}
$$


and

$$
\begin{aligned}
\psi_{3}(X, y)= & \left(\sqrt{K_{x} K_{y}}\right)\left\{\sum_{q=1}^{Q}\left[C_{q} \frac{\sinh \left[N_{q}\left(S_{X}+a_{X}-X\right)\right]}{\cosh \left(N_{q} S_{X}\right)} \cos \left(N_{q} y\right)\right]\right. \\
& +\sum_{p=1}^{P}\left[B_{p} \frac{\cosh \left(N_{p} y\right)}{\cosh \left(N_{p} H_{3}\right)} \cos \left[N_{p}\left(X-a_{X}\right)\right]\right] \\
& \left.-\sum_{m=1}^{M}\left[G_{m} \frac{\cosh \left[N_{m}\left(H_{3}-y\right)\right]}{\sinh \left(N_{m} H_{3}\right)} \cos \left[N_{m}\left(X-a_{X}\right)\right]\right]\right\},
\end{aligned}
$$

where the constants of integration in the stream functions are being conveniently chosen to be zero by assuming $\psi_{1}(X=0, y)=0, \psi_{2}\left(X=S_{X}+a_{X}, y\right)=0$, and $\psi_{3}\left(X=S_{X}+a_{X}, y\right)=0$. It is important to note here that $\psi_{3}$ diverges when measured exactly at the inner bunds; we now show this fact for the first inner bund but the same procedure can be followed to ascertain this fact for the other inner bunds as well. Substituting $G_{m}$ of Eq. A10 in Eq. 34 and simplifying, we find $\psi_{3}$ at the first inner bund (i.e., $\psi_{3}\left(X=S_{X 1}+a_{X}, y=0\right)$ separating two ponding depths, $\delta_{1}$ and $\delta_{2}$, to have a term like

$$
\sum_{m=1}^{M \rightarrow \infty}\left(2 \delta_{1} / S_{X} N_{m}\right) \operatorname{coth}\left(N_{m} H_{3}\right) \cos ^{2}\left(N_{m} S_{X 1}\right) .
$$

Just as we have done in showing the divergence of $Q_{\text {top }}$ for situations where $\delta_{1} \neq 0$ but $\varepsilon_{X}=0$ at the same time, here also, if we consider $\operatorname{coth}\left(N_{m} H_{3}\right)$ to approximately reduce to -1 after expanding first three terms, the above infinite series can be expressed as

$$
-\sum_{m=4}^{M \rightarrow \infty}\left(2 \delta_{1} / S_{X} N_{m}\right) \cos ^{2}\left(N_{m} S_{X 1}\right)
$$

after the first three terms of the series; we now show that this series diverges. Plugging $N_{m}$ into this series and simplifying, we find it to reduce to the form

$$
\omega(\text { say })=\frac{4 \delta_{1}}{\pi} \sum_{m=4}^{M \rightarrow \infty}\left(\frac{1}{2 m-1}\right) \cos ^{2}\left\{[(1-2 m) \alpha]\left(\frac{\pi}{2}\right)\right\},
$$

where

$$
\alpha=S_{X 1} / S_{X}(0<\alpha<1) .
$$

It is to be noted that

$$
0 \leq \cos ^{2}\left\{[(1-2 m) \alpha]\left(\frac{\pi}{2}\right)\right\} \leq 1
$$


for all values of $m \in\{1,2,3, \ldots\}$, the set of positive integers (for $\omega, m$ starts from 4$)$. There can be two possibilities for a chosen $\alpha$, namely,

$$
\cos ^{2}\left\{[(1-2 m) \alpha]\left(\frac{\pi}{2}\right)\right\} \neq 0
$$

for any value of $m \in\{4,5,6, \ldots\}$ or

$$
\cos ^{2}\left\{[(1-2 m) \alpha]\left(\frac{\pi}{2}\right)\right\}=0
$$

for a set of positive integers given by $\left\{m_{n 1}, m_{n 2}, m_{n 3}, \ldots\right\}$ where $m_{n i} \in$ $\{4,5,6, \ldots\}$. Let us first consider the first case and let $M_{\min }=$ minimum of

$$
\cos ^{2}\left\{[(1-2 m) \alpha]\left(\frac{\pi}{2}\right)\right\}
$$

for any $m \in\{4,5,6, \ldots\}$; then we have

$$
M_{\min } \frac{4 \delta_{1}}{\pi} \sum_{m=4}^{M \rightarrow \infty}\left(\frac{1}{2 m-1}\right)<\frac{4 \delta_{1}}{\pi} \sum_{m=4}^{M \rightarrow \infty}\left(\frac{1}{2 m-1}\right) \cos ^{2}\left\{[(1-2 m) \alpha]\left(\frac{\pi}{2}\right)\right\} .
$$

But the left hand side of this inequality, namely $M_{\min } \frac{4 \delta_{1}}{\pi}\left\{\frac{1}{7}+\frac{1}{9}+\frac{1}{11}+\ldots\right\}$, diverges and hence so will be the right hand side of the inequality. Now, we consider the second case where

$$
\cos ^{2}\left\{[(1-2 m) \alpha]\left(\frac{\pi}{2}\right)\right\}
$$

becomes zero for any $m \in\left\{m_{n 1}, m_{n 2}, m_{n 3}, \ldots\right\}$. To show that $\omega$ also diverges for this case as well, we first split the series in two parts

$$
\begin{aligned}
\omega(\text { say }) & =\frac{4 \delta_{1}}{\pi} \sum_{m_{n i}}^{M \rightarrow \infty}\left(\frac{1}{2 m-1}\right) \cos ^{2}\left\{[(1-2 m) \alpha]\left(\frac{\pi}{2}\right)\right\} \\
& +\frac{4 \delta_{1}}{\pi} \sum_{m}^{M \rightarrow \infty}\left(\frac{1}{2 m-1}\right) \cos ^{2}\left\{[(1-2 m) \alpha]\left(\frac{\pi}{2}\right)\right\},
\end{aligned}
$$

where $m$ of the second term of Eq. 35 belongs to the set $\{4,5,6, \ldots\} \backslash$ $\left\{m_{n 1}, m_{n 2}, m_{n 3}, \ldots\right\}$, the set of positive integers $\left\{m_{p 1}, m_{p 2}, m_{p 3}, \ldots\right\}$ (say). But the first term of Eq. 35 is zero (since $\cos ^{2}\left\{[(1-2 m) \alpha]\left(\frac{\pi}{2}\right)\right\}=0$ for all values of $\left.m_{n i}\right)$; thus, we can write this equation as 


$$
\omega=\frac{4 \delta_{1}}{\pi} \sum_{m}^{M \rightarrow \infty}\left(\frac{1}{2 m-1}\right) \cos ^{2}\left\{[(1-2 m) \alpha]\left(\frac{\pi}{2}\right)\right\}
$$

now, following exactly the same procedure as we have done for the first case, here also we can write the inequality

$$
M_{\min }^{\prime} \frac{4 \delta_{1}}{\pi} \sum_{m}^{M \rightarrow \infty}\left(\frac{1}{2 m-1}\right)<\frac{4 \delta_{1}}{\pi} \sum_{m}^{M \rightarrow \infty}\left(\frac{1}{2 m-1}\right) \cos ^{2}\left\{[(1-2 m) \alpha]\left(\frac{\pi}{2}\right)\right\}
$$

where $M_{\text {min }}^{\prime}=$ minimum of $\cos ^{2}\left\{[(1-2 m) \alpha]\left(\frac{\pi}{2}\right)\right\}$ for any $m \in\{4,5,6, \ldots\} \backslash$ $\left\{m_{n 1}, m_{n 2}, m_{n 3}, \ldots\right\}=\left\{m_{p 1}, m_{p 2}, m_{p 3}, \ldots\right\}$. Now,

$$
M_{\min }^{\prime} \frac{4 \delta_{1}}{\pi} \sum_{m}^{M \rightarrow \infty}\left(\frac{1}{2 m-1}\right)=M_{\min }^{\prime} \frac{4 \delta_{1}}{\pi}\left\{\frac{1}{2 m_{p 1}-1}+\frac{1}{2 m_{p 2}-1}+\frac{1}{2 m_{p 3}-1}+\ldots\right\}
$$

diverges and hence,

$$
\frac{4 \delta_{1}}{\pi} \sum_{m}^{M \rightarrow \infty}\left(\frac{1}{2 m-1}\right) \cos ^{2}\left\{[(1-2 m) \alpha]\left(\frac{\pi}{2}\right)\right\}
$$

also diverges. Thus, we see that $\psi_{3}\left(X=S_{X 1}+a_{X}, y=0\right)$ diverges for all possible cases. In the same way, we can also show that $\psi_{3}$ diverges exactly at the locations of the other inner bunds as well.

For clarity of presentation, the stream functions are generally first normalized before being used for plotting. For clarity of presentation, the normalization of the streamlines are carried out as under

and

$$
\psi_{1}^{n}(X, y)=1-\frac{\psi_{1}(X, y)}{\psi_{3}\left(a_{X}+\varepsilon_{X}, 0\right)}, \quad \psi_{2}^{n}(X, y)=1-\frac{\psi_{2}(X, y)}{\psi_{3}\left(a_{X}+\varepsilon_{X}, 0\right)},
$$

$$
\psi_{3}^{n}(X, y)=1-\frac{\psi_{3}(X, y)}{\psi_{3}\left(a_{X}+\varepsilon_{X}, 0\right)},
$$

where $\psi_{1}^{n}, \psi_{2}^{n}$, and $\psi_{3}^{n}$ are the normalized stream functions corresponding to sub-domains 1, 2 and 3, respectively, of Fig. 1.

The travel time of a water particle from any arbitrary point in the flow domain to a recipient ditch can also be determined from the known velocity functions (Eqs. 11-16) by following a simple iterative procedure as mentioned by Grove et al. (1970). Suppose a particle is at a location $(x, y)$ falling in the $i$ th domain $(i=1,2,3)$ of the drainage space at a time $t$; then naturally, at time $t+\Delta t$, it will traverse a horizontal distance, $\Delta x=V_{x i} \Delta t / \eta$, and a vertical distance, $\Delta y=V_{y i} \Delta t / \eta$, where $\eta$ is the porosity of the soil. Thus, at time $t+\Delta t$, the new coordinate location of the particle would be $(x+\Delta x$, 
$y+\Delta y)$ Now, the horizontal and vertical velocities of the particle at time $t+\Delta t$ in its new position $(x+\Delta x, y+\Delta y)$ can be estimated using the relevant velocity expressions given by Eqs. 11-16; once these velocities are known, like before, we can easily find the position of the particle at $t+2 \Delta t$. The procedure can be continued till the particle is fully traced up to a recipient ditch. We would like to point out here that the travel times as portrayed in Figs. 7 and 8 have been estimated using the technique just mentioned.

\section{MODEL VERIFICATION AND DISCUSSIONS}

\subsection{Verification of the proposed solution}

As mentioned before, the ponded ditch drainage problem solved here can be considered as an extension of the problem taken by Barua and Alam (2013) from that of a fully penetrating ditch drainage system to that of a partially penetrating one. Thus, if $H_{3}$ in Fig. 1 is allowed to approach $h$, the solution obtained here should approach the solution of the fully penetrating ditch drainage problem as obtained by Barua and Alam (2013). Thinking in this line, we have carried out a comparison of the time dependent top discharges as predicted by our model for increasing values of $\mathrm{H}_{3}$ with the ones obtained using the fully penetrating analytical model of Barua and Alam (2013) when the flow parameters of Fig. 1 are taken as shown in Table 1. As can be seen,

Table 1

Comparison of computed drain discharge values as obtained from the proposed model for a few flow situations of Fig. 1 with the corresponding values obtained from the analytical work of Barua and Alam (2013) when the parameters of the flow problem of Fig. 1 are taken as $S=5 \mathrm{~m}, h=1 \mathrm{~m}, a=0.25 \mathrm{~m}$, $S_{s}=0.001 \mathrm{~m}^{-1}, \delta_{j}=0 \mathrm{~m}, \varepsilon=0 \mathrm{~m}, K_{x} / K_{y}=1 / 1\left(K_{x}=1 \mathrm{~m} /\right.$ day, $K_{y}=1 \mathrm{~m} /$ day $)$

\begin{tabular}{|c|c|c|c|c|}
\hline \multirow{3}{*}{$\begin{array}{c}\text { Depth } \\
\text { of penetration } \\
\text { of ditch drains } \\
H_{3}=H_{1} \\
\text { [m] }\end{array}$} & \multicolumn{4}{|c|}{ Discharge per unit length of a ditch $\left[\mathrm{m}^{3} / \mathrm{day} / \mathrm{m}\right]$ as obtained from } \\
\hline & $\begin{array}{c}\text { Barua and Alam's } \\
\text { solution } \\
H_{3}=H_{1}=h \\
{[\mathrm{~m}]}\end{array}$ & $\begin{array}{l}\text { Proposed } \\
\text { solution }\end{array}$ & $\begin{array}{c}\text { Barua and Alam's } \\
\text { solution } \\
H_{3}=H_{1}=h \\
{[\mathrm{~m}]}\end{array}$ & $\begin{array}{c}\text { Proposed } \\
\text { solution }\end{array}$ \\
\hline & \multicolumn{2}{|c|}{$t=25 \mathrm{~s}$} & \multicolumn{2}{|c|}{$t=100 \mathrm{~s}$} \\
\hline 0.45 & \multirow{5}{*}{1.1091} & 0.5619 & \multirow{5}{*}{1.4580} & 0.9673 \\
\hline 0.55 & & 0.6875 & & 1.1118 \\
\hline 0.65 & & 0.8766 & & 1.2473 \\
\hline 0.75 & & 1.0305 & & 1.3531 \\
\hline 0.85 & & 1.0983 & & 1.4094 \\
\hline
\end{tabular}


for the considered flow situation, with the increase of $H_{3}$ values, the discharge predictions are getting increasing closer to the full penetrating discharge values of 1.1091 and $1.4580 \mathrm{~m}^{3} /$ day $/ \mathrm{m}$ corresponding to the tested times of 25 and $100 \mathrm{~s}$, respectively. As our model could successfully reproduce the discharge values close to the fully penetrating situation of the ditch drains (i.e., when $\mathrm{H}_{3}$ is being extended close to $h$ ), the way it should be, we conclude that the model proposed here for the partially penetrating ponded ditch drainage problem has been developed correctly.

To have a further check on our analytical model, we also performed a MODFLOW (Chiang and Kinzelbach 2001) verification of the same for a specific flow situation of Fig. 1, where we have considered $h=1 \mathrm{~m}$, $H_{3}=0.5 \mathrm{~m}, H_{1}=0.25 \mathrm{~m}, S=5 \mathrm{~m}, \quad a=0.25 \mathrm{~m}, \quad \delta_{j}=0.1 \mathrm{~m}, \varepsilon=0.05 \mathrm{~m}$, $K_{x}=1 \mathrm{~m} /$ day, $K_{y}=0.25 \mathrm{~m} /$ day, and $S_{s}=0.001 \mathrm{~m}^{-1}$. To formulate such a ponded drainage model in the MODFLOW platform, a hypothetical ponded soil of surface area of $15 \mathrm{~m}$ by $5 \mathrm{~m}$ and thickness of $1 \mathrm{~m}$ was first considered and then simulated with the help of a grid network comprising 152 rows, 107 columns, and 22 layers. Thus, the grid cells considered for modeling were having the row spacing as $0.1 \mathrm{~m}$, the column spacing as $0.05 \mathrm{~m}$ and the thickness of each cell as $0.05 \mathrm{~m}$. All the cells of the last layer (i.e., the 22nd layer) were made inactive so as to represent the impervious layer underlying the soil column and all the cells of the 1st layer starting from the 8th column to the 106th column and the 2 nd row to the 151th row were given a constant value of $0.1 \mathrm{~m}$ so as to represent a uniform ponding depth of $0.1 \mathrm{~cm}$ on the surface of the soil. The no-flow boundary on the centroidal plane in between the ditches was introduced by making all the cells falling in the 1st layer and continuing up to the 21 st layer of the 107 th column inactive. Also, the noflow northern and southern boundaries of the model were represented by making all the cells falling in the vertical planes of the 1st and the 152th rows and starting from the 7 th column to the 106th column inactive. The ditch bank of $0.05 \mathrm{~m}$ width was simulated by making all the cells falling in the 7th column of the 1st layer and running from the 2 nd row to the 151th row in that column inactive. The semi-bottom width of $0.25 \mathrm{~m}$ was modeled by assigning all the cells falling in the 2 nd to the 6th columns in the 11th layer with a constant value of $-0.25 \mathrm{~m}$. The side of the half-filled ditch having a water level of $0.25 \mathrm{~m}$, as measured from the surface of the soil, was simulated by assigning a constant cell value of $-.05 \mathrm{~m}$ for all the cells falling in the 6th column of the second layer, $-.1 \mathrm{~m}$ for all the cells falling in the 6 th column of the 3rd layer and so on up to the 6th layer, after which a constant value of -0.25 was imposed to all the cells of the 6th column up to the 11 th layer. The no-flow boundary condition on the plane passing through the centre and below the bottom of the ditch was modeled by making all the cells starting from the 12th layer and moving up to the 21 st layer of the 1st col- 
umn inactive. The horizontal and vertical hydraulic conductivities of $1 \mathrm{~m} /$ day and $0.25 \mathrm{~m} /$ day, respectively, and the specific storage of $0.001 \mathrm{~m}^{-1}$ of the soil were then inputted for all the active cells of the model.

With the above definition of the model in place, a transient MODFLOW run was then carried out and the hydraulic head contours obtained from the run for two time steps were compared with the corresponding analytically obtained values from our proposed model. Figure 2 shows such a comparison. As may be seen, our analytically obtained values for the considered flow situation for both the time steps are matching very closely with the corresponding MODFLOW predicted values, thereby verifying once again the rightness of the developed solution. We would like to point out that we have considered here the plane passing through the 76th row for extracting the numerically obtained hydraulic heads for comparison with our analytical model. This is because this zone is located halfway between the northern and

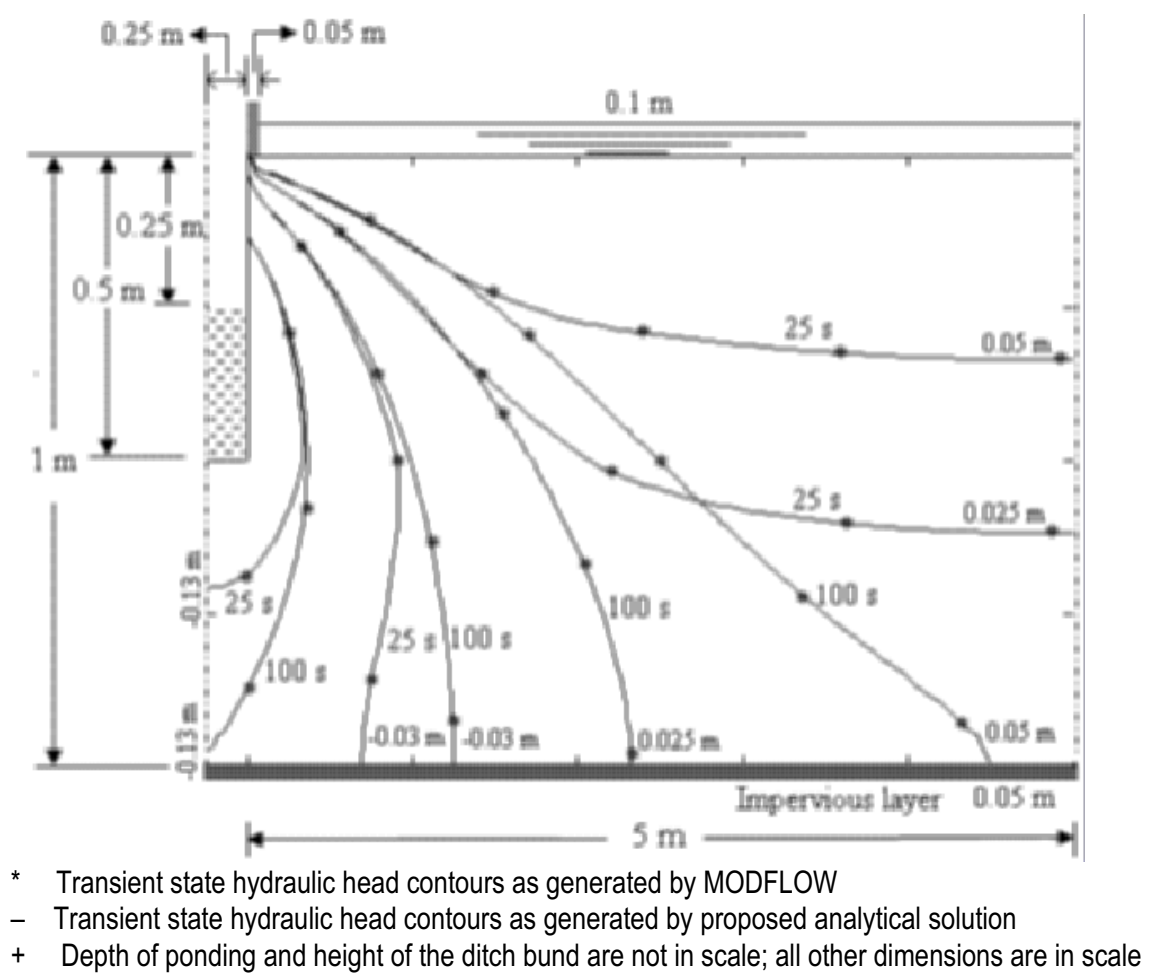

Fig. 2. Comparison of hydraulic head contours as obtained from the proposed analytical solution with the corresponding MODFLOW generated contours for two different time steps when the parameters of the flow problem of Fig. 1 are taken as: $S=5 \mathrm{~m}, h=1 \mathrm{~m}, H_{3}=0.5 \mathrm{~m}, H_{1}=0.25 \mathrm{~m}, a=0.25 \mathrm{~m}, S_{s}=0.001 \mathrm{~m}^{-1}, \delta_{j}=0.1 \mathrm{~m}$, $\varepsilon=0.05 \mathrm{~m}$, and $K_{x} / K_{y}=4 / 1\left(K_{x}=1 \mathrm{~m} /\right.$ day, $K_{y}=0.25 \mathrm{~m} /$ day $)$. 
southern boundaries of the numerical model and hence at the farthest distance between these two boundaries. It is to be noted that the analytical model developed here for the partially penetrating ponded ditch drainage problem is based on the assumption of two-dimensional flow, a condition which will ideally be satisfied if the ponded field is assumed to be of infinite size. The MODFLOW model considered here for comparison with our analytical solution, however, is a finite area model with the distance between the northern and the southern sides of the model restricted to only $15 \mathrm{~m}$ (152 rows). But it was observed that, even with a lesser separation of about $12 \mathrm{~m}$ between the northern and southern boundaries of the model instead of the $15 \mathrm{~m}$ separation taken in this model in between these boundaries, for the considered drainage situation, a sufficiently good approximation of twodimensional flow could be achieved in the vertical plane passing midway in between these boundaries.

\subsection{Discussions}

Figure 3 clearly shows that the time taken by a partially penetrating ponded ditch drainage system to reach steady state may be considerable if the ditches are being installed in a soil with low values of directional conductivities and a high value of specific storage, particularly for situations where the separation between the adjacent ditches is quite large and the underlying impervious layer lies at a sufficiently large distance from the bottom of the ditches. It is worth noting here that the hydraulic conductivity of many soils like silty clay loam, dense clay, glacial tills, and clayey paddy soils (Hendry 1982, Chen et al. 2002, Tabuchi 2004, Stibinger 2009, MacDonald et al. 2012) may be quite low; also, the specific storage of many unconfined aquifers may be quite high as well (Neuman 1975), particularly for aquifers in glacial tills (Grisak and Cherry 1975, Sharp 1984, Jones et al. 1992, Shaver 1998, Chen and Chang 2003). Further, as mentioned before, since soils with high anisotropy ratios also do frequently occur in nature we see that the transient duration of a partially penetrating ditch drainage system in these soils may be quite high. From Fig. $3 \mathrm{~b}$ and c, we also observe that the specific storage has a strong influence on the transient duration of a ponded drainage system - a decrease of the specific storage alone from 0.001 to $0.0001 \mathrm{~m}^{-1}$ for the concerned flow situations has caused the time for the top discharge to attain steady state to decrease from about 30 to about 4 hours. It can also be inferred from Fig. 3 that both top discharge as well as discharge through the sides and bottom of a ditch are pretty sensitive to the level of water in the ditch with the discharge values for an empty ditch far outweighing those of a quarterly or a half-filled ditch at all times of simulation of a partially ponded ditch drainage system. 

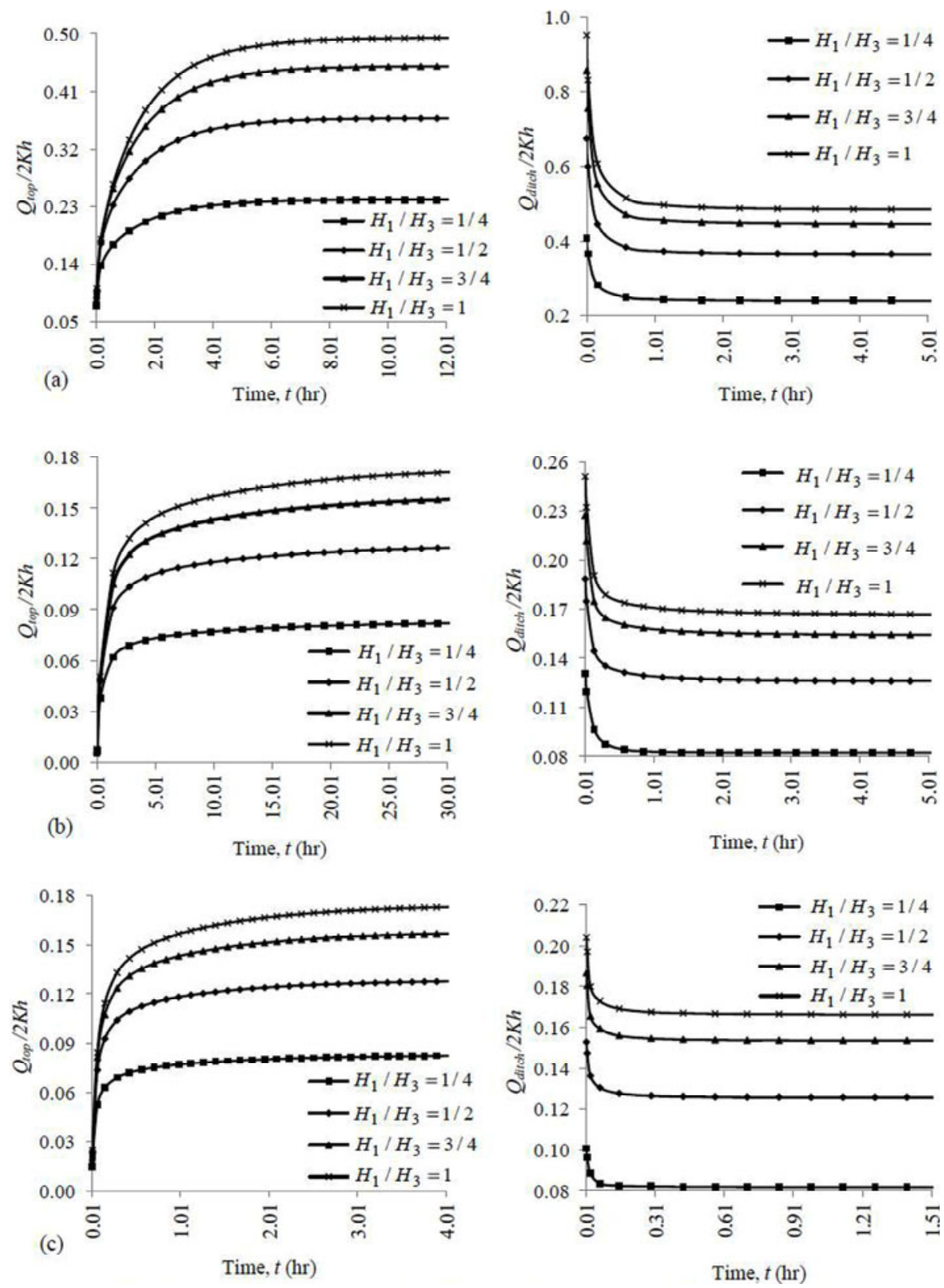

Fig. 3. Variations of $Q_{\text {top }} / 2 K h$ and $Q_{\text {ditch }} / 2 K h$ ratios with time for different $H_{1} / H_{3}$ ratios when: (a) $h=2 \mathrm{~m}, S_{s}=0.001 \mathrm{~m}^{-1}$; (b) $h=6 \mathrm{~m}, S_{s}=0.001 \mathrm{~m}^{-1}$; and (c) $h=6 \mathrm{~m}$, $S_{s}=0.0001 \mathrm{~m}^{-1}$; and the other parameters of the flow problem of Fig. 1 are taken as: $S=50 \mathrm{~m}, H_{3}=1 \mathrm{~m}, a=0.25 \mathrm{~m}, \delta_{j}=0 \mathrm{~m}, \varepsilon=0 \mathrm{~m}$, and $K_{x} / K_{y}=25 / 1\left(K_{x}=0.5 \mathrm{~m} /\right.$ day, $K_{y}=0.02 \mathrm{~m} /$ day). 

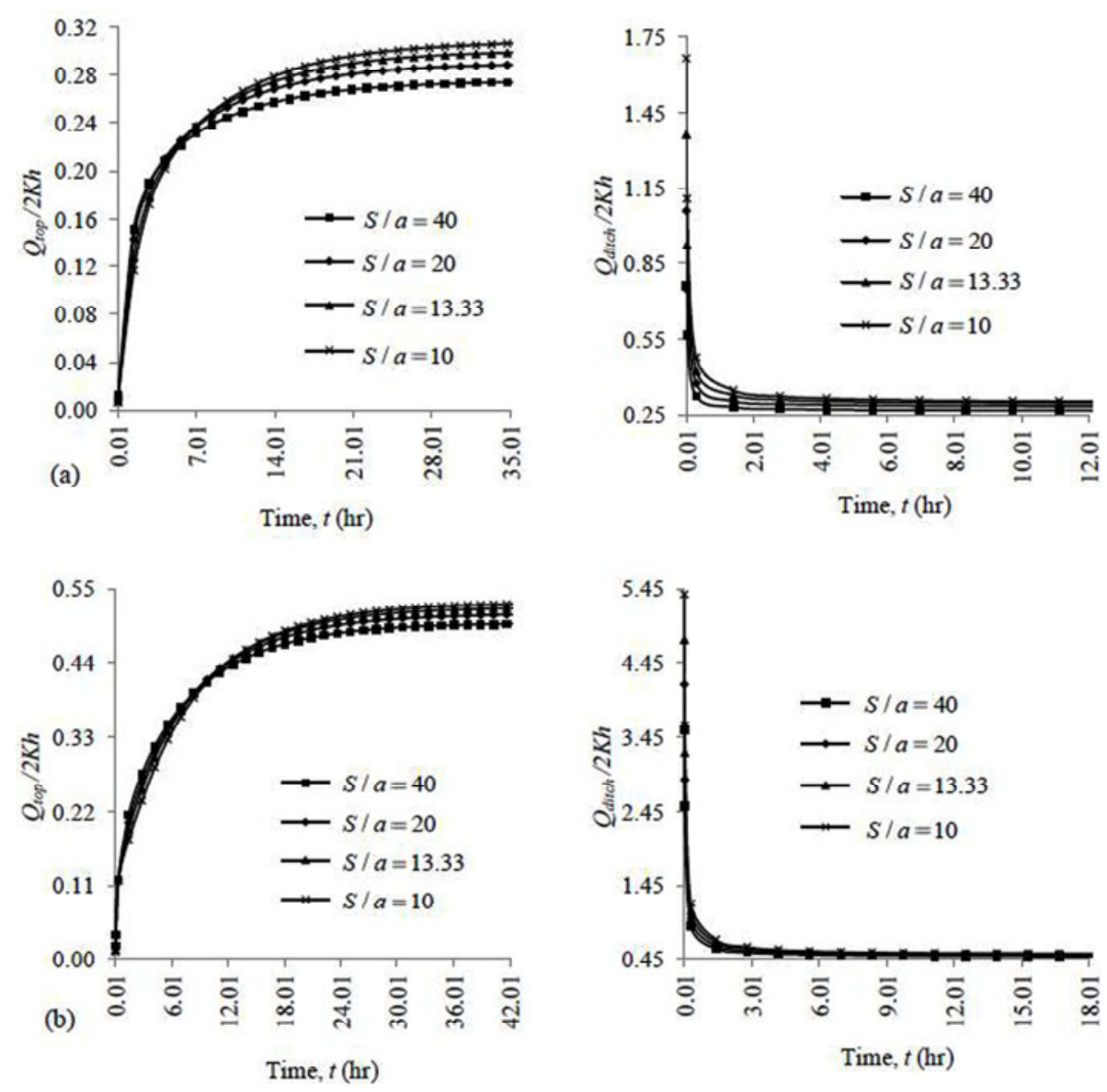

Fig. 4. Variations of $Q_{\text {top }} / 2 K h$ and $Q_{\text {ditch }} / 2 K h$ ratios with time for different $S / a$ ratios when: (a) $H_{1}=H_{3}=1.5 \mathrm{~m}$, (b) $H_{1}=H_{3}=3 \mathrm{~m}$; and the other parameters of the flow problem of Fig. 1 are taken as: $S=10 \mathrm{~m}, h=6 \mathrm{~m}, \delta_{j}=0 \mathrm{~m}, \varepsilon=0 \mathrm{~m}, S_{s}=0.0008 \mathrm{~m}^{-1}$, and $K_{x} / K_{y}=1 / 1\left(K_{x}=0.0254 \mathrm{~m} /\right.$ day, $K_{y}=0.0254 \mathrm{~m} /$ day $)$.

Figure 4 also corroborates the fact that the time to reach steady state for a partially penetrating ditch drainage system draining a ponded field comprising of a low conductivity soil $(0.0254 \mathrm{~m} /$ day, i.e., one inch per day - glencoe silty soil; Kirkham 1949) may be quite high, particularly if the ditches are being dug to a relatively deeper depth into the soil as measured with respect to the thickness of the soil. Thus, as may be observed, the top discharge for the flow situations in Fig. $4 \mathrm{~b}$ require about 42 hours to stabilize to the steady state whereas for the flow situations of Fig. $4 \mathrm{a}$, this figure is turning out to be about 35 hours only. We also see from these figures that the width of the 
ditch drains may not be having much of an impact on the surface discharge as well as on the bottom and side discharges of the ditches, specifically for ponded drainage scenarios where the spacing between the adjacent ditches is much higher than that of the width of the ditches.

Figure 5 shows the distribution of hydraulic gradient on the side and bottom of a ditch receiving water from a ponded field for a few flow situations
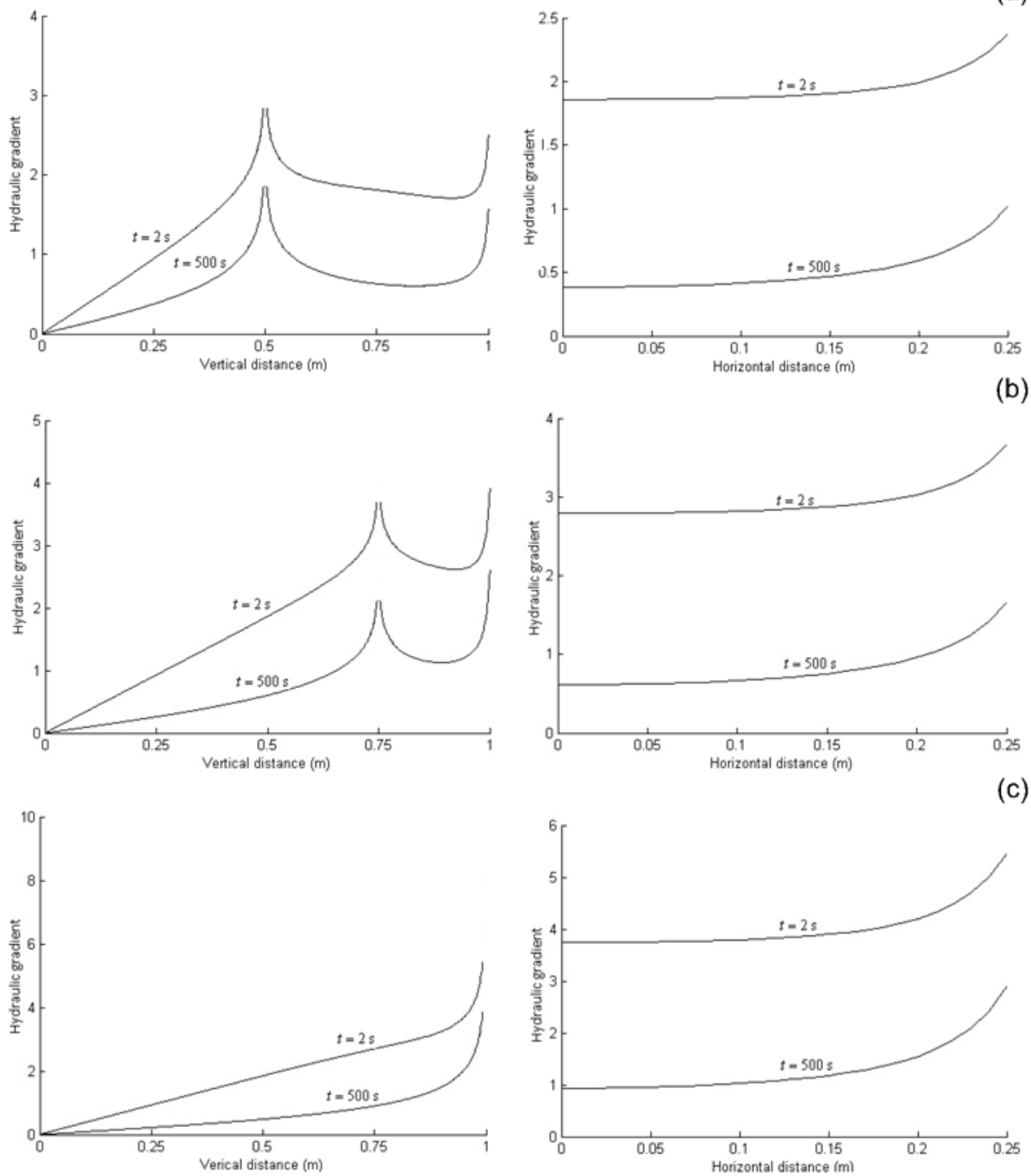

Fig. 5. Variation of hydraulic gradient at two different times at the face and bottom of a ditch when: (a) $H_{1}=0.5 \mathrm{~m}$, (b) $H_{1}=0.75 \mathrm{~m}$, (c) $H_{1}=1 \mathrm{~m}$; and the other parameters of Fig. 1 are taken as: $S=5 \mathrm{~m}, h=2 \mathrm{~m}, H_{3}=1 \mathrm{~m}, a=0.25 \mathrm{~m}, \delta_{j}=0 \mathrm{~m}$, $\varepsilon=0 \mathrm{~m}, S_{s}=0.001 \mathrm{~m}^{-1}$, and $K_{x} / K_{y}=1 / 1\left(K_{x}=1 \mathrm{~m} /\right.$ day, $K_{y}=1 \mathrm{~m} /$ day $)$. 
of Fig. 1. It should be noted that the hydraulic gradients at the boundary of a stream/ditch can be taken as a measure of the effect of subsurface drainage on incipient gully formation at the banks of a stream/ditch when the stream/ditch is running in bottomland areas having water levels lower than that of the surrounding water table (Römkens 2009, 2010). It is interesting to observe that the exit gradients at the ditch are quite sensitive to time in the transient phase of simulation of a ditch drainage system and that the exit gradients at the sides as well as on the bottom face of a ditch keep on increasing with the decrease of water level in the ditch, approaching progressively increasing values as the water level approaches the bottom face of the ditch.

It is also worth noting here that the higher exit gradients occur in the neighborhood where the level of water in a ditch meets the sides of the ditch.

From Fig. 6 we observe that the velocity distribution at the surface of a uniformly ponded ditch drainage scenario is pretty uneven with the velocity field falling rapidly as one moves away from the ditches. This has been observed to be true for both isotropic as well as anisotropic soils and also for both small as well as large times of simulation of a uniformly ponded drainage system. This finding is in concordant with the observations of Kirkham (1965), Youngs (1994), Barua and Tiwari (1995), Youngs and LeedsHarrison (2000), Mirjat and Rose (2009), Römkens (2009), Chahar and Vadodaria (2008a, b; 2012), Barua and Alam (2013), and others who also observed that the velocity field at the surface of a ponded ditch drainage system rapidly decreases with the increase in distance from the centre of the ditches. However, from Fig. 6a and b, we also see that, considering all other factors to remain the same, an increase in the anisotropy ratio of a soil column has an improving effect and a decrease of anisotropy ratio of a soil has a deteriorating affect, on the uniformity of surface velocity distribution of a uniformly ponded ditch drainage system. As most of the natural soils have a tendency to exhibit a higher water transmitting capacity along the bedding planes in comparison to that across the planes, the intrinsic anisotropy ratio of most soils, thus, in general, has a positive influence on the uniformity of distribution of the vertical velocities at the surface of a uniformly ponded ditch drainage system. From Fig. $6 \mathrm{~b}$ and c, it can further be observed that magnitude of the ponding depth at the surface of the soil of a ponded ditch drainage scenario also plays an important part in deciding the velocity distribution (and hence the time varying top discharge function as well) at the surface of the soil; a change of the ponding depth from $0 \mathrm{~m}$ in the flow situation of Fig. $6 \mathrm{~b}$ to $0.10 \mathrm{~m}$ by keeping all the other parameters of the flow problem same as before (Fig. 6c) has resulted in shifting upward the velocity profiles corresponding to both the $1 \mathrm{~min}$ and the steady state of simulation the system with the 1 min profile showing relatively higher velocities at distances away 

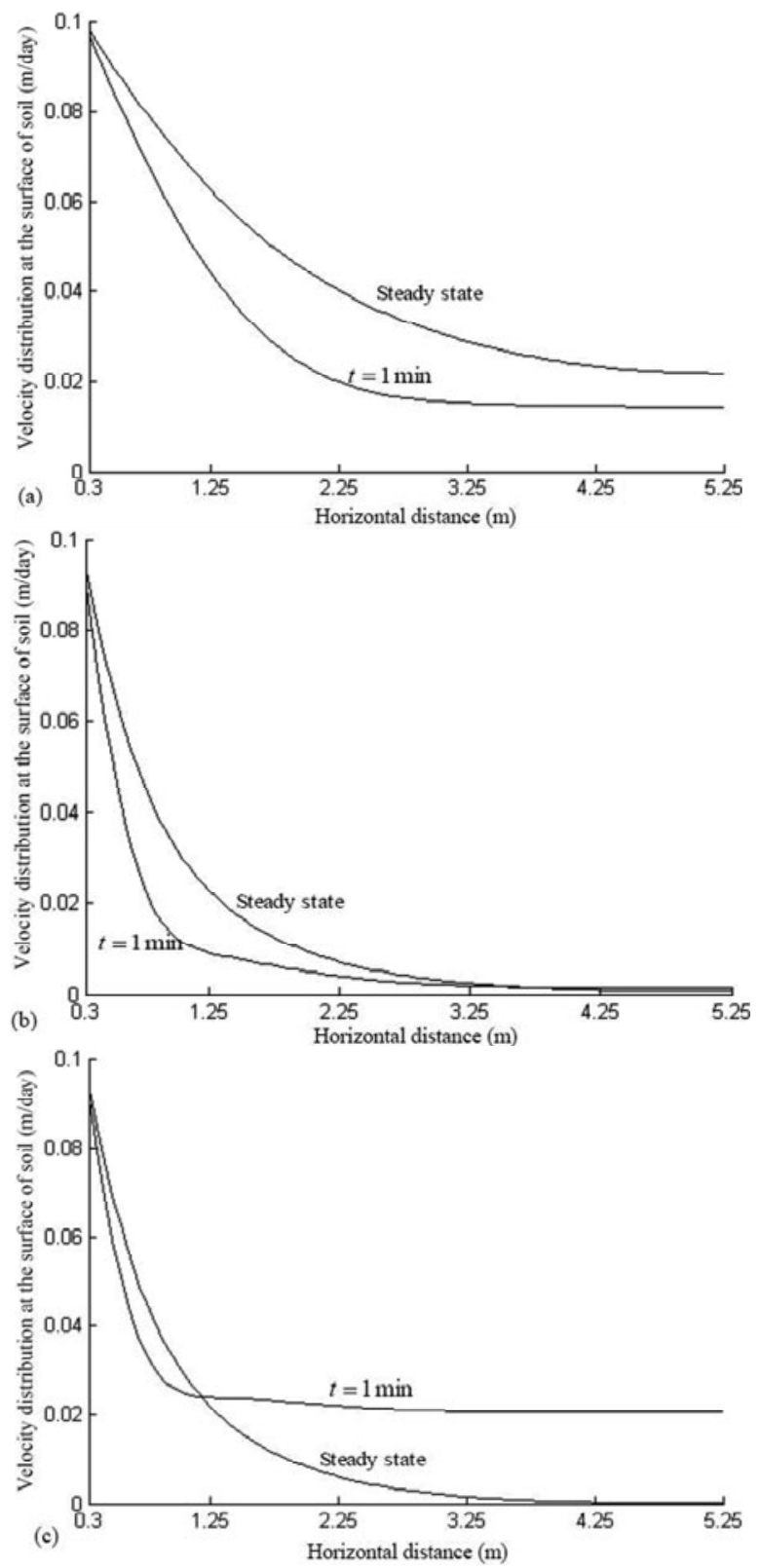

Fig. 6. Vertical velocity distribution at the surface of the soil at two different times when: (a) $\delta_{j}=0 \mathrm{~m}, K_{x} / K_{y}=10 / 1 \quad\left(K_{x}=1 \mathrm{~m} /\right.$ day, $K_{y}=0.1 \mathrm{~m} /$ day $),(\mathrm{b}) \delta_{j}=0 \mathrm{~m}$, $K_{x} / K_{y}=1 \quad\left(K_{x}=0.1 \mathrm{~m} /\right.$ day, $K_{y}=0.1 \mathrm{~m} /$ day $), \quad$ and $\quad(\mathrm{c}) \quad \delta_{j}=0.1 \mathrm{~m}, \quad K_{x} / K_{y}=1$ $\left(K_{x}=0.1 \mathrm{~m} /\right.$ day, $K_{y}=0.1 \mathrm{~m} /$ day $)$, and the other parameters of the flow problem of Fig. 1 are taken as $S=5 \mathrm{~m}, h=1.5 \mathrm{~m}, H_{3}=1 \mathrm{~m}, H_{1}=0.5 \mathrm{~m}, a=0.25 \mathrm{~m}, \varepsilon=0.05 \mathrm{~m}$, $S_{s}=0.001 \mathrm{~m}^{-1}$. 
from the ditches as compared to the steady state profile. This means that, considering all the other variables to remain the same, an increase in the depth of ponding in a partially ponded drainage system may result not only in an increase of the top discharges corresponding to different times of running of the system but may also result in considerable lifting of the tails of the velocity profiles, particularly for velocity profiles being traced for early times of operation of the system. The velocity profiles of Fig. 6 also show that considerable volume of water may be drained during the transient duration of a uniformly ponded drainage system, particularly from areas lying close to the drains.

From Fig. 7, it is obvious that the introduction of a variable ponding field of the nature as shown for the chosen ditch drainage scenario has improved considerably the uniformity of the streamline distribution at the surface of the soil as compared to the situation when the surface of the soil for such a flow situation is subject to a uniform ponding depth only. Thus, whereas about $83 \%$ of the total flow to a ditch for the uniform ponding scenario of Fig. $7 \mathrm{a}$ is being contributed from a surficial distance of only $1.5 \mathrm{~m}$ on either side of the ditch, the corresponding figure, when the flow situation of Fig. 7a is subject to a variable ponding field of the type as shown Fig. 7b, is about $66 \%$ only. Further, as can be observed in these figures, the imposition of this variable ponding field to the considered flow geometry is also making the travel times of water particles originating from the surface of the soil to the ditches relatively more uniform as compared to the situation when the considered drainage situation is being subjected to only a constant ponding depth of $0.15 \mathrm{~m}$ on the surface of the soil. Thus, whereas water particles starting from the surface of the soil from distances of $0.5,1.5,2.5$, and $3.5 \mathrm{~m}$, respectively, and traversing on the normalized streamlines 0.4510 , $0.8262,0.9424$, and 0.9861 for the flow situation of Fig. $7 \mathrm{a}$ are taking $0.2604,0.9028,2.5608$, and 5.8507 days, respectively, to move to a vertical distance of $0.5 \mathrm{~m}$ from the surface of the soil, the corresponding figures for the water particles moving on the normalized streamlines $0.2853,0.6654$, 0.7929 , and 0.9041 for the variable ponding scenario of Fig. $7 \mathrm{~b}$ are now working out to be only $0.4080,0.7552,1.7274$, and 1.8403 days, respectively. We would also like to point out here that the steady discharge rate for the uniformly ponded flow situation of Fig. 7a turns out to be $1.8038 \mathrm{~m}^{3} /$ day $/ \mathrm{m}$ and that for the variable ponded situation of Fig. $7 \mathrm{~b}$ to be $1.4741 \mathrm{~m}^{3} /$ day $/ \mathrm{m}$, a value which is actually less than that of the uniform ponded situation. Hence, it can be concluded that, in comparison to a uniform ponded ditch drainage system, a properly worked out variable ditch ponding drainage system for a concerned drainage situation may result in considerable improvement not only on the uniformity of distribution of the streamlines on the drainage space but on the uniformity of travel times of water particles as 

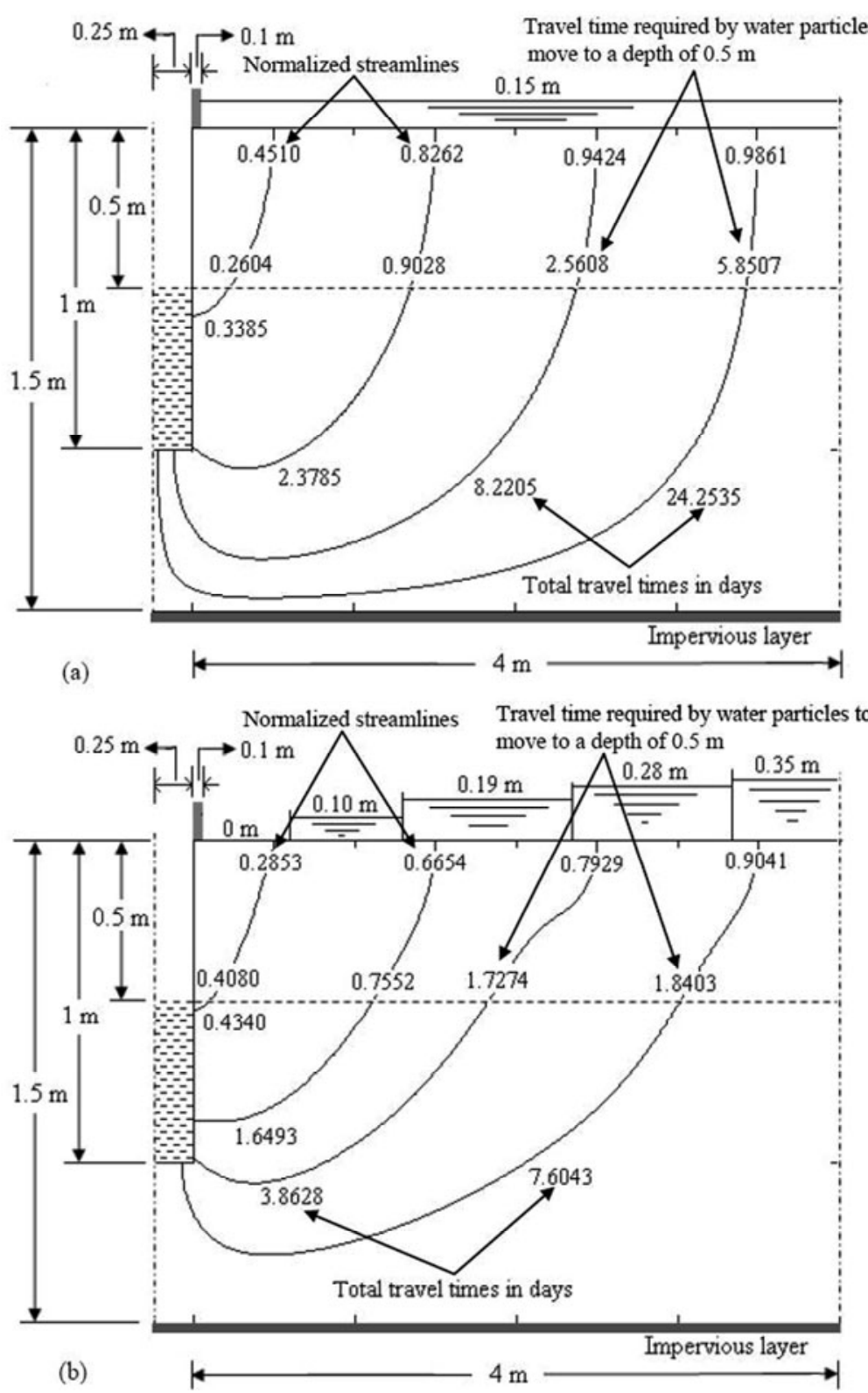

Fig. 7. Fluid travel times for water particles (in days) starting from the surface of the soil to the ditches when: (a) $\delta_{j}=0.15 \mathrm{~m}$, and (b) $S_{1}=0.60 \mathrm{~m}, S_{2}=1.3 \mathrm{~m}$, $S_{3}=2.35 \mathrm{~m}, \quad S_{4}=3.35 \mathrm{~m}, \quad \delta_{1}=0 \mathrm{~m}, \quad \delta_{2}=0.10 \mathrm{~m}, \quad \delta_{3}=0.19 \mathrm{~m}, \quad \delta_{4}=0.28 \mathrm{~m}$, $\delta_{5}=0.35 \mathrm{~m}$, and the other parameters of Fig. 1 are taken as: $S=4 \mathrm{~m}, h=1.5 \mathrm{~m}$, $H_{3}=1 \mathrm{~m}, H_{1}=0.5 \mathrm{~m}, a=0.25 \mathrm{~m}, \eta=0.3, \varepsilon=0.1 \mathrm{~m}, K_{x} / K_{y}=1 / 1 \quad\left(K_{x}=1 \mathrm{~m} /\right.$ day, $K_{y}=1 \mathrm{~m} /$ day). 
well from their sources of origin at the surface of the soil to a desired horizontal plane below the surface of the soil or to the recipient ditches; further, the water needed for reclaiming a salt affected soil via a variable ponding ditch drainage system, may actually turn out to be less than that needed for reclaiming the same soil via a uniform ponding ditch drainage system even though the former system, as has been just shown, may lead to a much better and cheaper cleaning of the soil profile as compared to the latter system. It is also interesting to see that a water particle starting from a surficial distance of $3.5 \mathrm{~m}$ from the edge of the ditch for the flow situation of Fig. 7a is taking about 24 days to complete its journey to the ditch but the corresponding figure for the flow situation of Fig. $7 \mathrm{~b}$ is turning out to be about 8 days only. Also, if the anisotropy ratio of the soil for the flow situation of Fig. $7 \mathrm{~b}$ is changed simply from 1 to that of 5 by decreasing the vertical conductivity, the uniformity of streamline distribution in the concerned drainage space, as can be observed in Fig. 8a, gets markedly improved. As soils in nature mostly tend to exhibit higher horizontal conductivities than their vertical conductivities, the inbuilt orientations of directional conductivities of most soils, thus, favour a more equitable distribution of streamlines in a ponded drainage space. From Figs. $7 b$ and $8 b$, c, we further see that the water particle travel times in a ponded drainage space are influenced by the depth and level of water in the ditches; expectedly, a decrease in the water level of the ditches causes the travel times to fall and the same has also been observed to be true if the depth of the drains is made to increase.

The analytical model proposed here can also be used to work out the upper limit of fall of water level of a waterlogged soil in a desired duration due to a partially penetrating subsurface ditch drainage system. For example, if we consider the flow situation of Fig. 7a, we find the volume of water seeping from the surface of the soil in between two adjacent ditches at the end of the first 1 hour to be $0.0774 \mathrm{~m}^{3}$ per unit length of the ditches and at the end of the first 5 hours to be $0.3811 \mathrm{~m}^{3}$ per unit length of the ditches. If we now allow the water level to fall, the depth of fall would then be $9.918 \mathrm{~mm}$ $((0.0774 \times 1000) /[2 \times(4-0.1)])$ at the end of the first 1 hour and $48.863 \mathrm{~mm}$ $((0.3811 \times 1000) /[2 \times(4-0.1)])$ at the end of the first 5 hours. It is to be noted that these are the upper limits of fall of the water level, since the volumes which are being used to determine these falls have been estimated based on the assumption that the ponded water level of $0.15 \mathrm{~m}$ is a constant at all times of simulation of the ditch drainage system. In reality, however, if the waterlogged field is not fed by any external source of water, the ponded water level on the surface of the soil would then be not a constant one but would keep on progressively decreasing with time. 


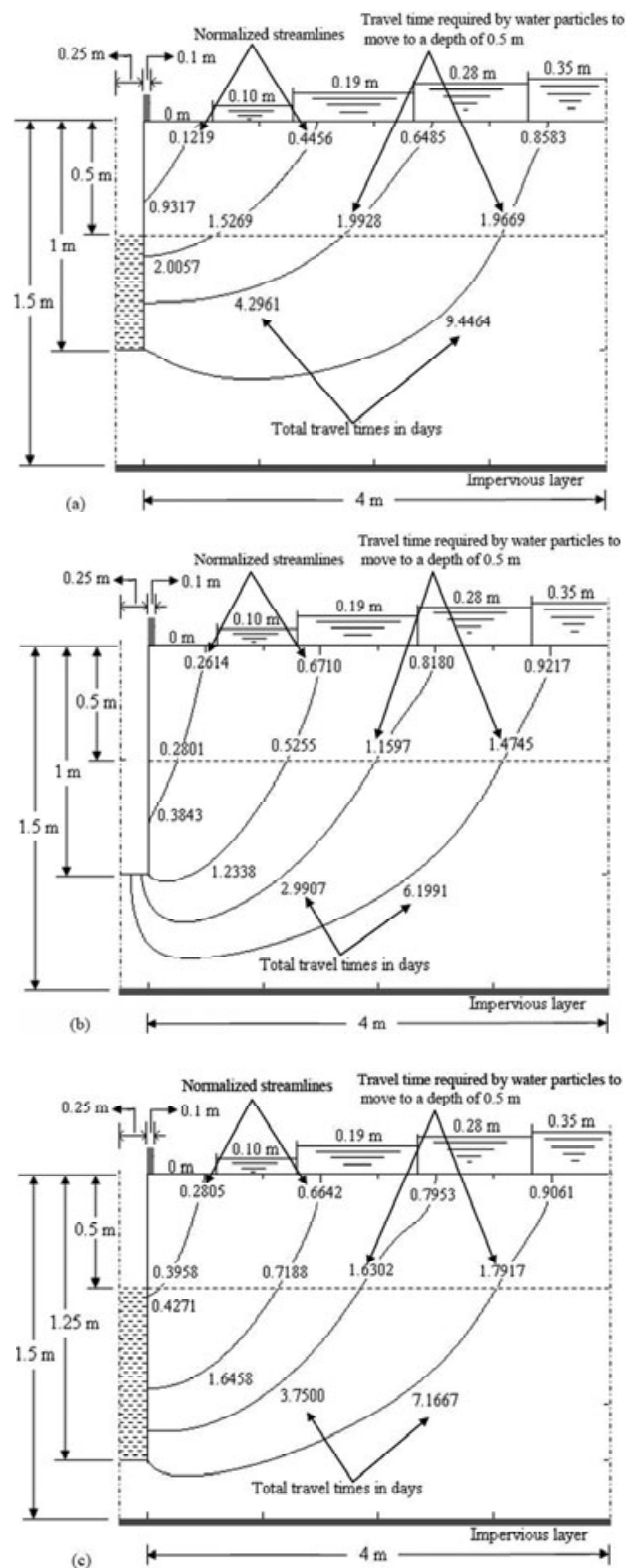

Fig. 8. Fluid travel times for water particles (in days) starting from the surface of the soil to the ditches when: (a) $H_{1}=0.5 \mathrm{~m}, H_{3}=1 \mathrm{~m}, K_{x} / K_{y}=5 / 1 \quad\left(K_{x}=1 \mathrm{~m} /\right.$ day, $K_{y}=0.2 \mathrm{~m} /$ day $),\left(\right.$ b) $H_{1}=1 \mathrm{~m}, H_{3}=1 \mathrm{~m}, K_{x} / K_{y}=1 / 1\left(K_{x}=1 \mathrm{~m} /\right.$ day, $K_{y}=1 \mathrm{~m} /$ day $)$, (c) $H_{1}=0.5 \mathrm{~m}, H_{3}=1.25 \mathrm{~m}, K_{x} / K_{y}=1 / 1\left(K_{x}=1 \mathrm{~m} /\right.$ day, $K_{y}=1 \mathrm{~m} /$ day $)$, and the other parameters of Fig. 1 are taken as: $S=4 \mathrm{~m}, h=1.5 \mathrm{~m}, a=0.25 \mathrm{~m}, \eta=0.3, \varepsilon=0.1 \mathrm{~m}$, $S_{1}=0.60 \mathrm{~m}, \quad S_{2}=1.3 \mathrm{~m}, \quad S_{3}=2.35 \mathrm{~m}, \quad S_{4}=3.35 \mathrm{~m}, \quad \delta_{1}=0 \mathrm{~m}, \quad \delta_{2}=0.10 \mathrm{~m}$, $\delta_{3}=0.19 \mathrm{~m}, \delta_{4}=0.28 \mathrm{~m}, \delta_{5}=0.35 \mathrm{~m}$. 


\section{CONCLUSIONS}

An analytical solution has been proposed for predicting transient seepage into an array of equally spaced ditch drains partially penetrating a homogeneous and anisotropic soil underlain by an impervious barrier, the drains being fed by a variable ponding field at the surface of the soil. The soil has been assumed to be of finite thickness, the surface of the soil horizontal and of infinite extent and the drains have been assumed to be separated from each other by a finite distance. The solution can account for anisotropy of the soil, partial penetration of the drains and finite bottom width of the ditches as well; thus, it is of a pretty general nature. The assumption of infinitely long parallel drains in an infinitely large horizontal field is transforming what actually is a three-dimensional problem to a two-dimensional one. The solution to the boundary value problem has been attempted by carrying out an appropriate domain discretization of the flow domain and then solving the governing equation in each of the sub-domains, taking due care at the same time to see that the necessary boundary and interfacial conditions pertaining to each of the sub-domains have also been concurrently satisfied. The separation of variable method in association with a right mix of single and double Fourier series have been utilized to obtain the necessary expressions of the hydraulic head function pertaining to each of the sub-domains. The validity of the proposed solution has been confirmed by comparing the discharge values obtained from the solution for a specific configuration of the problem at two time steps with the corresponding discharge values obtained from an existing fully penetrating analytical solution of the problem. A MODFLOW check of the proposed solution has also been performed for a particular configuration of the problem.

The study shows that the time taken by a partially penetrating ponded ditch drainage system in a homogenous and anisotropic soil to go to steady state may be considerable (for example, when the ditches are running empty, the times taken by the drainage systems of Figs. $3 \mathrm{~b}$ and $4 \mathrm{~b}$ to go to steady state are around 30 and 42 hours, respectively) if the directional conductivities of the soil are low and the specific storage and anisotropy ratio of the soil high. This is all the more true if the soil is of a larger thickness and the depth of penetration of the drains is relatively high as scaled with respect to the thickness of the soil. The width of the ditch drains receiving water from a ponded field does not seem to have much of an influence on the drain discharge as well as on the discharge taking place through the surface of the ponded field but the level of water in the ditches has been observed to have a strong influence on the surface as well as on the side and bottom discharges of the ditches. The study clearly demonstrates that flow to a ditch drainage system from a uniformly ponded field is mostly confined to areas close to 
the drains and that considerable uniformity in the movement of water in the drainage space, both in terms of quantity of flow and in water particle travel times from the surface of the soil to a recipient ditch or a desired horizontal plane below the surface of the soil (say, up to the root zone of a crop), can be brought about by introducing a proper ponding field over the surface of the soil specific to a drainage situation. Thus, leaching of a salt affected soil via a variable ponding field ditch drainage system may result in considerable saving of both water and time as compared to leaching of the same utilizing a uniform ponded ditch drainage system.

The study also clearly shows that the exit gradients at the boundaries of a ditch are very sensitive to the time of simulation of a ditch drainage system as well as to the position of the water level in the ditch. The exit gradients are found to be higher for early times of simulation of the system and are also observed to vary inversely with the level of water in the ditches. Thus, the possibility of breaching the banks of a stream/ditch due to sudden lowering of water level in the stream/ditch with respect to the surrounding water table and the ensuing subsurface seepage to the stream/ditch because of it, is more likely to occur at the early transient stage of movement of the groundwater to the stream/ditch, particularly in the neighborhood where the water level in the stream/ditch touches the soil surface. The analytical model developed here can also be utilized to design a network of subsurface ditch drains for lowering the level of flood water in an area by a desired amount in a specific time. Thus, the ditch drainage model presented here, apart from being made use of in designing ditch drains for reclaiming a salt affected soil, can also be used to design drains for reclaiming a flooded field as well within a desired time.

\section{Appendix}

\section{Determination of Fourier coefficients}

Referring to Section 2, it can be seen that Eq. 5 satisfies conditions II, III, and VI, Eq. 6 satisfies VIII and IX, and Eq. 7 satisfies XV as a consequence of their very definitions. To evaluate $C_{q}$, we apply conditions XIII and XIV to Eq. 7; thus, we have at $X=a_{X}$

$$
\sum_{q=1}^{Q} C_{q} \sin \left(N_{q} y\right)=-y, \quad 0<y \leq H_{1},
$$




$$
\sum_{q=1}^{Q} C_{q} \sin \left(N_{q} y\right)=-H_{1}, \quad H_{1}<y \leq H_{3} .
$$

Allowing $Q$ to increase indefinitely in the above expression, $C_{q}$ can then be evaluated by running a Fourier series on the interval $0<y<H_{3}$, thus, we have

$$
C_{q}=-\frac{2}{H_{3}}\left[\int_{0}^{H_{1}} y \sin \left(N_{q} y\right) d y+\int_{H_{1}}^{H_{3}} H_{1} \sin \left(N_{q} y\right) d y\right] .
$$

Eq. A3, upon simplification, yields

$$
C_{q}=-\left(\frac{2}{H_{3}}\right)\left[\frac{\sin \left(N_{q} H_{1}\right)}{\left(N_{q}\right)^{2}}\right] .
$$

For evaluating the constants $G_{m}$, we apply conditions XVI, XVII and XVIII to Eq. 7 to get at $y=0$

$$
\begin{array}{ll}
\sum_{m=1}^{M} G_{m} \sin \left[N_{m}\left(X-a_{X}\right)\right]=\delta_{1}, & a_{X}<X<S_{X 1}+a_{X}, \\
\sum_{m=1}^{M} G_{m} \sin \left[N_{m}\left(X-a_{X}\right)\right]=\delta_{j}, & S_{X(j-1)}+a_{X}<X<S_{X j}+a_{X}, \\
\sum_{m=1}^{M} G_{m} \sin \left[N_{m}\left(X-a_{X}\right)\right]=\delta_{N_{0}}, & S_{X\left(N_{0}-1\right)}+a_{X}<X<S_{X}+a_{X},
\end{array}
$$

where

$$
S_{X j}=\left(\sqrt{\frac{K_{y}}{K_{x}}}\right) S_{j} .
$$

Now making use of the Fourier expansion in the range $a_{X}<X<S_{X}+a_{X}$, we have an expression for $G_{m}$, after letting $M \rightarrow \infty$, as

$$
\begin{aligned}
G_{m} & =\frac{2}{S_{X}}\left\{\int_{a_{X}}^{S_{X 1}+a_{X}} \delta_{1} \sin \left[N_{m}\left(X-a_{X}\right)\right] d X+\sum_{j=2}^{N_{0}-1} \int_{S_{X(j-1)}+a_{X}}^{S_{X j}+a_{X}} \delta_{j} \sin \left[N_{m}\left(X-a_{X}\right)\right] d X\right. \\
& \left.+\int_{S_{X\left(N_{0}-1\right)}+a_{X}}^{S_{X}+a_{X}} \delta_{N_{0}} \sin \left[N_{m}\left(X-a_{X}\right)\right] d X\right\} .
\end{aligned}
$$

Simplifying the above integral, we get 


$$
\begin{aligned}
G_{m} & =\frac{2}{S_{X}}\left\{\left(\frac{\delta_{1}}{N_{m}}\right)\left[1-\cos \left(N_{m} S_{X 1}\right)\right]+\sum_{j=2}^{N_{0}-1}\left(\frac{\delta_{j}}{N_{m}}\right)\left[\cos \left(N_{m} S_{X(j-1)}\right)-\cos \left(N_{m} S_{X j}\right)\right]\right. \\
& \left.+\left(\frac{\delta_{N_{0}}}{N_{m}}\right) \cos \left(N_{m} S_{X\left(N_{0}-1\right)}\right)\right\} .
\end{aligned}
$$

Now, applying condition IV to Eqs. 5 and 6, respectively, we have at $X=a_{X}$

$$
\sum_{r=1}^{R} D_{r} \sin \left[N_{r}\left(y-H_{3}\right)\right]-H_{1}=\sum_{w=1}^{W} F_{w} \sin \left[N_{w}\left(y-H_{3}\right)\right]-H_{1}, \quad H_{3}<y<h .
$$

Thus, $D_{r}$ can be evaluated using a Fourier series expansion in $H_{3}<y<h$ if we assume $R$ in the above expression to go to infinity; considering such is the case, we then have

$$
D_{r}=\frac{2}{h-H_{3}}\left\{\int_{H_{3}}^{h} \sum_{w=1}^{W}\left[F_{w} \sin \left[N_{w}\left(y-H_{3}\right)\right]\right] \sin \left[N_{r}\left(y-H_{3}\right)\right] d y\right\} .
$$

The above integral survives only when $r=w$ and zero otherwise. Thus, for $r=w$

$$
D_{r}=F_{w}
$$

and for $r \neq w$

$$
D_{r}=0
$$

We now apply condition $\mathrm{V}$ to Eqs. 5 and 6, respectively, to get at $X=a_{X}$

$$
\begin{aligned}
\sum_{w=1}^{W} F_{w} N_{w} \tanh \left(N_{w} a_{X}\right) \sin \left[N_{w}\left(y-H_{3}\right)\right] & =-\sum_{r=1}^{R} D_{r} N_{r} \tanh \left(N_{r} S_{X}\right) \sin \left[N_{r}\left(y-H_{3}\right)\right] \\
& +\sum_{n=1}^{N} E_{n} \frac{\cosh \left[N_{n}(h-y)\right]}{\sinh \left[N_{n}\left(h-H_{3}\right)\right]} N_{n}, \quad\left(H_{3}<y<h\right) .
\end{aligned}
$$

The constants $F_{w}$ can then be evaluated, considering $W \rightarrow \infty$, as a Fourier expansion in $H_{3}<y<h$, thus, we have

$$
\begin{aligned}
& F_{w} N_{w} \tanh \left(N_{w} a_{X}\right)=\left(\frac{-2}{h-H_{3}}\right)\left\{\int_{H_{3}}^{h} \sum_{r=1}^{R}\left[D_{r} N_{r} \tanh \left(N_{r} S_{X}\right) \sin \left[N_{r}\left(y-H_{3}\right)\right]\right] \times\right. \\
& \left.\times \sin \left[N_{w}\left(y-H_{3}\right)\right] d y-\int_{H_{3}}^{h} \sum_{n=1}^{N}\left[E_{n} \frac{\cosh \left[N_{n}(h-y)\right]}{\sinh \left[N_{n}\left(h-H_{3}\right)\right]} N_{n}\right] \sin \left[N_{w}\left(y-H_{3}\right)\right] d y\right\} .
\end{aligned}
$$


Naming the first integral of Eq. A16 as $I^{(1)}$ and the second integral as $I^{(2)}$, the above equation can then be expressed as

$$
F_{w}=\left(\frac{-2}{h-H_{3}}\right) \operatorname{coth}\left(N_{w} a_{X}\right)\left(\frac{1}{N_{w}}\right)\left[I^{(1)}-I^{(2)}\right] .
$$

Simplifying the above integrals, we have for $w=r$

$$
I^{(1)}=D_{r}\left(\frac{h-H_{3}}{2}\right) N_{r} \tanh \left(N_{r} S_{X}\right)
$$

and for $w \neq r$

$$
I^{(1)}=0
$$

and

$$
I^{(2)}=\sum_{n=1}^{N} E_{n}\left[\frac{N_{n} N_{w}}{\left(N_{w}\right)^{2}+\left(N_{n}\right)^{2}}\right] \operatorname{coth}\left[N_{n}\left(h-H_{3}\right)\right] .
$$

Applying now the equality of the hydraulic head condition $\mathrm{X}$ at the interface of regions II and III to Eqs. 6 and 7, respectively, we get at $y=H_{3}$

$$
\begin{aligned}
& \sum_{q=1}^{Q} C_{q} \frac{\cosh \left[N_{q}\left(S_{X}+a_{X}-X\right)\right]}{\cosh \left(N_{q} S_{X}\right)} \sin \left(N_{q} H_{3}\right)+\sum_{p=1}^{P} B_{p} \tanh \left(N_{p} H_{3}\right) \sin \left[N_{p}\left(X-a_{X}\right)\right]= \\
& \sum_{n=1}^{N} E_{n} \operatorname{coth}\left[N_{n}\left(h-H_{3}\right)\right] \sin \left[N_{n}\left(X-a_{X}\right)\right]-H_{1} .
\end{aligned}
$$

By letting $P \rightarrow \infty$, the constants $B_{p}$ can be evaluated by a Fourier series expansion in the range $a_{X}<X<S_{X}+a_{X}$, thus, we have

$$
\begin{aligned}
& B_{p} \tanh \left(N_{p} H_{3}\right)=\left(\frac{2}{S_{X}}\right)\left\{\int_{a_{X}}^{S_{X}+a_{X}} \sum_{n=1}^{N}\left[E_{n} \operatorname{coth}\left[N_{n}\left(h-H_{3}\right)\right] \sin \left[N_{n}\left(X-a_{X}\right)\right]\right]\right. \\
& \times \sin \left[N_{p}\left(X-a_{X}\right)\right] d X-\int_{a_{X}}^{S_{X}+a_{X}} \sum_{q=1}^{Q}\left[C_{q} \frac{\cosh \left[N_{q}\left(S_{X}+a_{X}-X\right)\right]}{\cosh \left(N_{q} S_{X}\right)} \sin \left(N_{q} H_{3}\right)\right] \\
& \left.\times \sin \left[N_{p}\left(X-a_{X}\right)\right] d X-\int_{a_{X}}^{S_{X}+a_{X}} H_{1} \sin \left[N_{p}\left(X-a_{X}\right)\right] d X\right\} .
\end{aligned}
$$

If we name the three integrals of Eq. A22 as $I^{(3)}, I^{(4)}$, and $I^{(5)}$, respectively, then Eq. A22 can be written as 


$$
B_{p}=\left(\frac{2}{S_{X}}\right) \operatorname{coth}\left(N_{p} H_{3}\right)\left[I^{(3)}-I^{(4)}-I^{(5)}\right] .
$$

Simplification of the first integral gives, for $p=n$

$$
I^{(3)}=E_{n} \operatorname{coth}\left[N_{n}\left(h-H_{3}\right)\right]\left(\frac{S_{X}}{2}\right)
$$

and for $p \neq n$

$$
I^{(3)}=0
$$

further, the other two integrals, upon simplification, reduce to

$$
I^{(4)}=\sum_{q=1}^{Q} C_{q}\left[\frac{N_{p} \sin \left(N_{q} H_{3}\right)}{\left(N_{p}\right)^{2}+\left(N_{q}\right)^{2}}\right]
$$

and

$$
I^{(5)}=\frac{H_{1}}{N_{p}} .
$$

Also, application of the flux equality condition XI at the interface of regions II and III to Eq. 6 and 7, respectively, yields at $y=H_{3}$

$$
\begin{aligned}
& \sum_{r=1}^{R} D_{r} N_{r} \frac{\cosh \left[N_{r}\left(S_{X}+a_{X}-X\right)\right]}{\cosh \left(N_{r} S_{X}\right)}-\sum_{n=1}^{N} E_{n} N_{n} \sin \left[N_{n}\left(X-a_{X}\right)\right]= \\
& =\sum_{p=1}^{P} B_{p} N_{p} \sin \left[N_{p}\left(X-a_{X}\right)\right]-\sum_{m=1}^{M} G_{m} N_{m} \frac{\sin \left[N_{m}\left(X-a_{X}\right)\right]}{\sinh \left(N_{m} H_{3}\right)} .
\end{aligned}
$$

Thus, $E_{n}$ can be evaluated, considering $N \rightarrow \infty$, by performing a Fourier run in $a_{X}<X<S_{X}+a_{X}$, hence, $E_{n}$ can be expressed as

$$
\begin{aligned}
E_{n} N_{n}= & \left(\frac{2}{S_{X}}\right)\left\{\int_{a_{X}}^{S_{X}+a_{X}} \sum_{r=1}^{R}\left[D_{r} N_{r} \frac{\cosh \left[N_{r}\left(S_{X}+a_{X}-X\right)\right]}{\cosh \left(N_{r} S_{X}\right)}\right] \sin \left[N_{n}\left(X-a_{X}\right)\right] d X\right. \\
& -\int_{a_{X}}^{S_{X}+a_{X}} \sum_{p=1}^{P}\left[B_{p} N_{p} \sin \left[N_{p}\left(X-a_{X}\right)\right]\right] \sin \left[N_{n}\left(X-a_{X}\right)\right] d X \\
& \left.+\int_{a_{X}}^{S_{X}+a_{X}} \sum_{m=1}^{M}\left[G_{m} N_{m} \frac{\sin \left[N_{m}\left(X-a_{X}\right)\right]}{\sinh \left(N_{m} H_{3}\right)}\right] \sin \left[N_{n}\left(X-a_{X}\right)\right] d X\right\} .
\end{aligned}
$$

Simplifying the above integrals, we get 


$$
E_{n}=\left(\frac{2}{S_{X}}\right)\left(\frac{1}{N_{n}}\right)\left[I^{(6)}-I^{(7)}+I^{(8)}\right],
$$

where

$$
I^{(6)}=\sum_{r=1}^{R} D_{r} \frac{N_{r} N_{n}}{\left[\left(N_{n}\right)^{2}+\left(N_{r}\right)^{2}\right]},
$$

for $p=n$

$$
I^{(7)}=B_{p} N_{p}\left(\frac{S_{X}}{2}\right)
$$

and for $p \neq n$

$$
I^{(7)}=0,
$$

for $m=n$

$$
I^{(8)}=G_{m}\left[\frac{N_{m}}{\sinh \left(N_{m} H_{3}\right)}\right]\left(\frac{S_{X}}{2}\right)
$$

and for $m \neq n$

$$
I^{(8)}=0 \text {. }
$$

Now, the linear equations resulting from Eqs. A12, A17, A23, and A30 can be solved using Gauss elimination or some other suitable method (Scarborough 1966) to obtain the constants $F_{w}, D_{r}, E_{n}$, and $B_{p}$; with the evaluation of these constants, all the constants involved in the steady state forms of the hydraulic head functions are thus determined and the boundary value problem for such a situation is thus solved.

We now propose to tackle the transient part of the problem by incorporating the initial condition into the solution domain. Towards that end, we modify the expressions of $\varphi_{1}$ and $\varphi_{3}$ a bit; we add the term

$$
\sum_{m_{2}=1}^{M_{2}} \sum_{n_{2}=1}^{N_{2}} A_{m_{2} n_{2}} \sin \left(N_{m_{2}} y\right) \sin \left[N_{n_{2}}\left(X-a_{X}\right)\right] \exp \left[-\frac{\left(\lambda_{m_{2} n_{2}}\right)^{2} t}{\left(K_{1}\right)^{2}}\right]
$$

in $\varphi_{1}$ and the term

$$
\sum_{m_{1}=1}^{M_{1}} \sum_{n_{1}=1}^{N_{1}} Z_{m_{1} n_{1}} \sin \left[N_{m_{1}}\left(y-H_{3}\right)\right] \cos \left(N_{n_{1}} X\right) \exp \left[-\frac{\left(\lambda_{m_{1} n_{1}}\right)^{2} t}{\left(K_{1}\right)^{2}}\right]
$$


in $\varphi_{3}$ with the understanding that the first term is zero in $0<X<a_{X}$, $H_{3}<y<h$ and the second term is also zero in $a_{X}<X<S_{X}+a_{X}, 0<y<H_{3}$. Inclusion of these terms in the original expressions for $\varphi_{1}$ and $\varphi_{3}$ would reduce them to

$$
\begin{aligned}
\varphi_{1}(X, y, t)= & \sum_{w=1}^{W} F_{w} \frac{\cosh \left(N_{w} X\right)}{\cosh \left(N_{w} a_{X}\right)} \sin \left[N_{w}\left(y-H_{3}\right)\right] \\
+ & \sum_{m_{1}=1}^{M_{1}} \sum_{n_{1}=1}^{N_{1}} Z_{m_{1} n_{1}} \sin \left[N_{m_{1}}\left(y-H_{3}\right)\right] \cos \left(N_{n_{1}} X\right) \exp \left[-\frac{\left(\lambda_{m_{1} n_{1}}\right)^{2} t}{\left(K_{1}\right)^{2}}\right] \\
+ & \sum_{m_{2}=1}^{M_{2}} \sum_{n_{2}=1}^{N_{2}} A_{m_{2} n_{2}} \sin \left(N_{m_{2}} y\right) \sin \left[N_{n_{2}}\left(X-a_{X}\right)\right] \exp \left[-\frac{\left(\lambda_{m_{2} n_{2}}\right)^{2} t}{\left(K_{1}\right)^{2}}\right]-H_{1}, \\
& \quad\left(0<X<a_{X}, \quad H_{3}<y<h\right),
\end{aligned}
$$

and

$$
\begin{aligned}
\varphi_{3}(X, y, t)= & \sum_{q=1}^{Q} C_{q} \frac{\cosh \left[N_{q}\left(S_{X}+a_{X}-X\right)\right]}{\cosh \left(N_{q} S_{X}\right)} \sin \left(N_{q} y\right) \\
& +\sum_{p=1}^{P} B_{p} \frac{\sinh \left(N_{p} y\right)}{\cosh \left(N_{p} H_{3}\right)} \sin \left[N_{p}\left(X-a_{X}\right)\right] \\
& +\sum_{m=1}^{M} G_{m} \frac{\sinh \left[N_{m}\left(H_{3}-y\right)\right]}{\sinh \left(N_{m} H_{3}\right)} \sin \left[N_{m}\left(X-a_{X}\right)\right] \\
& +\sum_{m_{1}=1}^{M_{1}} \sum_{n_{1}=1}^{N_{1}} Z_{m_{1} n_{1}} \sin \left[N_{m_{1}}\left(y-H_{3}\right)\right] \cos \left(N_{n_{1}} X\right) \exp \left[-\frac{\left(\lambda_{m_{1} n_{1}}\right)^{2} t}{\left.\left(K_{1}\right)^{2}\right]}\right. \\
& +\sum_{m_{2}=1}^{M_{2}} \sum_{n_{2}=1}^{N_{2}} A_{m_{2} n_{2}} \sin \left(N_{m_{2}} y\right) \sin \left[N_{n_{2}}\left(X-a_{X}\right)\right] \exp \left[-\frac{\left(\lambda_{m_{2} n_{2}}\right)^{2} t}{\left.\left(K_{1}\right)^{2}\right],} \quad\left(a_{X}<X<S_{X}+a_{X}, \quad 0<y<H_{3}\right) .\right.
\end{aligned}
$$

It is also worth noting at this stage that the derivative of the double summation term involving $A_{m_{2} n_{2}}$ above is not zero at $X=a_{X}$ for all $y \in\left(H_{3}, h\right)$ and the derivative of the double summation term involving $Z_{m_{1} n_{1}}$ above is also not zero at $y=H_{3}$ for all $X \in\left(a_{X}, S_{X}+a_{X}\right)$. We would like to state here that the expressions to be used for $\varphi_{1}$ and $\varphi_{3}$ are as given by Eqs. 5 
and 7, respectively; the alternate expressions of $\varphi_{1}$ and $\varphi_{3}$, as given by Eqs. A36 and A37 above, are provided for mathematical purpose only so that the constants $A_{m_{2} n_{2}}$ and $Z_{m_{1} n_{1}}$ can be adequately determined satisfying the initial condition of the problem together with the interfacial conditions in between the sub-domains.

As may be observed, the expressions for $\varphi_{1}, \varphi_{2}$, and $\varphi_{3}$ with the steady state coefficients $F_{w}, D_{r}, E_{n}$, and $B_{p}$ just been determined satisfy the interfacial conditions for all time $t>0$; to incorporate the initial condition and hence determine the coefficients $A_{m_{2} n_{2}}$ and $Z_{m_{1} n_{1}}$ of the hydraulic heads, we employ conditions XII, VII, and I to $\varphi_{3}$ (Eq. A37), $\varphi_{2}$ (Eq. 6), and $\varphi_{1}$ (Eq. A36), respectively.

Thus, we have $\varphi_{3}$ at $t=0$ as

$$
\begin{aligned}
& \sum_{q=1}^{Q} C_{q} \frac{\cosh \left[N_{q}\left(S_{X}+a_{X}-X\right)\right]}{\cosh \left(N_{q} S_{X}\right)} \sin \left(N_{q} y\right) \\
& +\sum_{p=1}^{P} B_{p} \frac{\sinh \left(N_{p} y\right)}{\cosh \left(N_{p} H_{3}\right)} \sin \left[N_{p}\left(X-a_{X}\right)\right] \\
& +\sum_{m=1}^{M} G_{m} \frac{\sinh \left[N_{m}\left(H_{3}-y\right)\right]}{\sinh \left(N_{m} H_{3}\right)} \sin \left[N_{m}\left(X-a_{X}\right)\right] \\
& +\sum_{m_{1}=1}^{M_{1}} \sum_{n_{1}=1}^{N_{1}} Z_{m_{1} n_{1}} \sin \left[N_{m_{1}}\left(y-H_{3}\right)\right] \cos \left(N_{n_{1}} X\right) \\
& +\sum_{m_{2}=1}^{M_{2}} \sum_{n_{2}=1}^{N_{2}} A_{m_{2} n_{2}} \sin \left(N_{m_{2}} y\right) \sin \left[N_{n_{2}}\left(X-a_{X}\right)\right]=0 .
\end{aligned}
$$

It can be observed in Eq. A38 that the $y$-bases of $Z_{m_{1} n_{1}}$ and $A_{m_{2} n_{2}}$ are not the same - whereas the former is defined for $H_{3}<y<h$, the latter is for the whole vertical length, namely $0<y<h$. In order that a Fourier series be run on the whole space comprising of the second and the third domains, we now express each term of $\sum_{m_{1}=1}^{M_{1}} \sum_{n_{1}=1}^{N_{1}} Z_{m_{1} n_{1}} \sin \left[N_{m_{1}}\left(y-H_{3}\right)\right] \cos \left(N_{n_{1}} X\right)$ as a Fourier series in $a_{X}<X<S_{X}+a_{X}, \quad 0<y<h$; thus, we have for each $m_{1}$ and $n_{1}$ $\left(1 \leq m_{1} \leq M_{1}, 1 \leq n_{1} \leq N_{1}\right)$

$$
Z_{m_{1} n_{1}} \sin \left[N_{m_{1}}\left(y-H_{3}\right)\right] \cos \left(N_{n_{1}} X\right)=\sum_{m_{2}=1}^{M_{2}} \sum_{n_{2}=1}^{N_{2}} P_{m_{2} n_{2}}^{m_{1} n_{1}} \sin \left(N_{m_{2}} y\right) \sin \left[N_{n_{2}}\left(X-a_{X}\right)\right]
$$


Performing a Fourier double run on $a_{X}<X<a_{X}+S_{X}, 0<y<h$ by letting $M_{2}$ and $N_{2}$ to increase to infinitely in Eq. A39, we have

$$
\begin{aligned}
& P_{m_{2} n_{2}}^{m_{1} n_{1}}=\left(\frac{2}{S_{X}}\right)\left(\frac{2}{h}\right)\left\{\int_{a_{X}}^{S_{X}+a_{X}} \int_{0}^{H_{3}}(0) \times \sin \left(N_{m_{2}} y\right) \sin \left[N_{n_{2}}\left(X-a_{X}\right)\right] d y d X\right. \\
& \left.+\int_{a_{X}}^{S_{X}+a_{X}} \int_{H_{3}}^{h} Z_{m_{1} n_{1}} \sin \left[N_{m_{1}}\left(y-H_{3}\right)\right] \cos \left(N_{n_{1}} X\right) \sin \left(N_{m_{2}} y\right) \sin \left[N_{n_{2}}\left(X-a_{X}\right)\right] d y d X\right\} .
\end{aligned}
$$

The first double integral obviously is zero; naming the second double integral of Eq. A40 as $I^{(9)}$ and expressing it as a product of two single integrals, $I_{a}^{(9)}$ and $I_{b}^{(9)}$ (one in $X$ and the other in $y$ ), we get

$$
I_{a}^{(9)}=\int_{H_{3}}^{h} \sin \left[N_{m_{1}}\left(y-H_{3}\right)\right] \sin \left(N_{m_{2}} y\right) d y
$$

and

$$
I_{b}^{(9)}=\int_{a_{X}}^{S_{X}+a_{X}} \cos \left(N_{n_{1}} X\right) \sin \left[N_{n_{2}}\left(X-a_{X}\right)\right] d X
$$

The integral of Eq. A41, upon simplification, yields for $\left(N_{m_{1}}\right)^{2}=\left(N_{m_{2}}\right)^{2}$

$$
I_{a}^{(9)}=\left(\frac{h-H_{3}}{2}\right) \cos \left(-N_{m_{1}} H_{3}\right)-\left\{\frac{\sin \left[\left(2 N_{m_{1}} h\right)-\left(N_{m_{1}} H_{3}\right)\right]-\sin \left(N_{m_{1}} H_{3}\right)}{4 N_{m_{1}}}\right\}
$$

and for $\left(N_{m_{1}}\right)^{2} \neq\left(N_{m_{2}}\right)^{2}$

$$
\begin{aligned}
I_{a}^{(9)} & =\left\{\frac{\sin \left[\left(N_{m_{1}}-N_{m_{2}}\right) h-\left(N_{m_{1}} H_{3}\right)\right]-\sin \left(-N_{m_{2}} H_{3}\right)}{2\left(N_{m_{1}}-N_{m_{2}}\right)}\right\} \\
& -\left\{\frac{\sin \left[\left(N_{m_{1}}+N_{m_{2}}\right) h-\left(N_{m_{1}} H_{3}\right)\right]-\sin \left(N_{m_{2}} H_{3}\right)}{2\left(N_{m_{1}}+N_{m_{2}}\right)}\right\} .
\end{aligned}
$$

Also, for $\left(N_{n_{1}}\right)^{2}=\left(N_{n_{2}}\right)^{2}, I_{b}^{(9)}$ works out to be

$I_{b}^{(9)}=\left(\frac{S_{X}}{2}\right) \sin \left(-N_{n_{2}} a_{X}\right)-\left\{\frac{\cos \left[\left(2 N_{n_{2}}\right)\left(S_{X}+a_{x}\right)-\left(N_{n_{2}} a_{X}\right)\right]-\cos \left(N_{n_{2}} a_{X}\right)}{4 N_{n_{2}}}\right\}$ 
and for $\left(N_{n_{1}}\right)^{2} \neq\left(N_{n_{2}}\right)^{2}$

$$
\begin{aligned}
I_{b}^{(9)}= & -\left\{\frac{\cos \left[\left(N_{n_{2}}-N_{n_{1}}\right)\left(S_{X}+a_{X}\right)-\left(N_{n_{2}} a_{X}\right)\right]-\cos \left(-N_{n_{1}} a_{X}\right)}{2\left(N_{n_{2}}-N_{n_{1}}\right)}\right\} \\
& -\left\{\frac{\cos \left[\left(N_{n_{2}}+N_{n_{1}}\right)\left(S_{X}+a_{X}\right)-\left(N_{n_{2}} a_{X}\right)\right]-\cos \left(N_{n_{1}} a_{X}\right)}{2\left(N_{n_{2}}+N_{n_{1}}\right)}\right\} .
\end{aligned}
$$

Thus, from Eqs. A41 and A42, Eq. A40 can be expressed as

$$
P_{m_{2} n_{2}}^{m_{1} n_{1}}=\left(\frac{2}{S_{X}}\right)\left(\frac{2}{h}\right)\left[Z_{m_{1} n_{1}} I_{a}^{(9)} I_{b}^{(9)}\right] \text {. }
$$

Plugging Eq. A39 in Eq. A38 and simplifying, we get

$$
\begin{aligned}
\sum_{m_{2}=1}^{M_{2}} \sum_{n_{2}=1}^{N_{2}}\left[A_{m_{2} n_{2}}+\left(\sum_{m_{1}=1}^{M_{1}} \sum_{n_{1}=1}^{N_{1}} P_{m_{2} n_{2}}^{m_{1} n_{1}}\right)\right] \sin \left(N_{m_{2}} y\right) \sin \left[N_{n_{2}}\left(X-a_{X}\right)\right]= \\
-\sum_{q=1}^{Q} C_{q} \frac{\cosh \left[N_{q}\left(S_{X}+a_{X}-X\right)\right]}{\cosh \left(N_{q} S_{X}\right)} \sin \left(N_{q} y\right) \\
\quad-\sum_{p=1}^{P} B_{p} \frac{\sinh \left(N_{p} y\right)}{\cosh \left(N_{p} H_{3}\right)} \sin \left[N_{p}\left(X-a_{X}\right)\right] \\
-\sum_{m=1}^{M} G_{m} \frac{\sinh \left[N_{m}\left(H_{3}-y\right)\right]}{\sinh \left(N_{m} H_{3}\right)} \sin \left[N_{m}\left(X-a_{X}\right)\right] \\
\left(a_{X}<X<S_{X}+a_{X}, \quad 0<y<H_{3}\right) .
\end{aligned}
$$

Applying now condition VII to Eq. 6, we get

$$
\begin{aligned}
\sum_{r=1}^{R} D_{r} & \frac{\cosh \left[N_{r}\left(S_{X}+a_{X}-X\right)\right]}{\cosh \left(N_{r} S_{X}\right)} \sin \left[N_{r}\left(y-H_{3}\right)\right] \\
& +\sum_{n=1}^{N} E_{n} \frac{\cosh \left[N_{n}(h-y)\right]}{\sinh \left[N_{n}\left(h-H_{3}\right)\right]} \sin \left[N_{n}\left(X-a_{X}\right)\right] \\
& +\sum_{m_{1}=1}^{M_{1}} \sum_{n_{1}=1}^{N_{1}} Z_{m_{1} n_{1}} \sin \left[N_{m_{1}}\left(y-H_{3}\right)\right] \cos \left(N_{n_{1}} X\right) \\
& +\sum_{m_{2}=1}^{M_{2}} \sum_{n_{2}=1}^{N_{2}} A_{m_{2} n_{2}} \sin \left(N_{m_{2}} y\right) \sin \left[N_{n_{2}}\left(X-a_{X}\right)\right]-H_{1}=0 .
\end{aligned}
$$


Like before, adjusting the bases of the double summation terms of the above equation, we get

$$
\begin{gathered}
\sum_{m_{2}=1}^{M_{2}} \sum_{n_{2}=1}^{N_{2}}\left[A_{m_{2} n_{2}}+\left(\sum_{m_{1}=1}^{M_{1}} \sum_{n_{1}=1}^{N_{1}} P_{m_{2} n_{2}}^{m_{1} n_{1}}\right)\right] \sin \left(N_{m_{2}} y\right) \sin \left[N_{n_{2}}\left(X-a_{X}\right)\right]=H_{1} \\
-\sum_{r=1}^{R} D_{r} \frac{\cosh \left[N_{r}\left(S_{X}+a_{X}-X\right)\right]}{\cosh \left(N_{r} S_{X}\right)} \sin \left[N_{r}\left(y-H_{3}\right)\right] \\
-\sum_{n=1}^{N} E_{n} \frac{\cosh \left[N_{n}(h-y)\right]}{\sinh \left[N_{n}\left(h-H_{3}\right)\right]} \sin \left[N_{n}\left(X-a_{X}\right)\right], \\
\quad\left(a_{X}<X<S_{X}+a_{X}, \quad H_{3}<y<h\right) .
\end{gathered}
$$

Now, from Eqs. A48 and A50, an expression for

$$
A_{m_{2} n_{2}}+\left(\sum_{m_{1}=1}^{M_{1}} \sum_{n_{1}=1}^{N_{1}} P_{m_{2} n_{2}}^{m_{m_{1}} n_{1}}\right)
$$

can be worked out by undertaking a double Fourier expansion in the range $a_{X}<X<S_{X}+a_{X}, 0<y<h$ by letting $M_{2} \rightarrow \infty$ and $N_{2} \rightarrow \infty$ in these equations; the ensuing relation works out to be

$$
\begin{aligned}
& A_{m_{2} n_{2}}+\left(\sum_{m_{1}=1}^{M_{1}} \sum_{n_{1}=1}^{N_{1}} P_{m_{2} n_{2}}^{m_{1} n_{1}}\right)=\left(\frac{2}{S_{X}}\right)\left(\frac{2}{h}\right)\left\{-\int_{a_{X}}^{S_{X}+a_{X}} \int_{0}^{H_{3}} \sum_{q=1}^{Q}\left[C_{q} \frac{\cosh \left[N_{q}\left(S_{X}+a_{X}-X\right)\right]}{\cosh \left(N_{q} S_{X}\right)} \sin \left(N_{q} y\right)\right] \times\right. \\
& \sin \left(N_{m_{2}} y\right) \sin \left[N_{n_{2}}\left(X-a_{X}\right)\right] d y d X-\int_{a_{X}}^{S_{X}+a_{X}} \int_{0}^{H_{3}} \sum_{p=1}^{P}\left[B_{p} \frac{\sinh \left(N_{p} y\right)}{\cosh \left(N_{p} H_{3}\right)} \sin \left[N_{p}\left(X-a_{X}\right)\right] \times\right. \\
& \sin \left(N_{m_{2}} y\right) \sin \left[N_{n_{2}}\left(X-a_{X}\right)\right] d y d X-\int_{a_{X}}^{S_{X}+a_{X}} \int_{0}^{H_{3}} \sum_{m=1}^{M}\left[G_{m} \frac{\sinh \left[N_{m}\left(H_{3}-y\right)\right]}{\sinh \left(N_{m} H_{3}\right)} \sin \left[N_{m}\left(X-a_{X}\right)\right]\right] \times \\
& \sin \left(N_{m_{2}} y\right) \sin \left[N_{n_{2}}\left(X-a_{X}\right)\right] d y d X+\int_{a_{X}}^{S_{X}+a_{X}} \int_{H_{3}}^{h} H_{1} \sin \left(N_{m_{2}} y\right) \sin \left[N_{n_{2}}\left(X-a_{X}\right)\right] d y d X \\
& -\int_{a_{X}}^{S_{X}+a_{X}} \int_{H_{3}}^{h} \sum_{r=1}^{R}\left[D_{r} \frac{\cosh \left[N_{r}\left(S_{X}+a_{X}-X\right)\right]}{\cosh \left(N_{r} S_{X}\right)} \sin \left[N_{r}\left(y-H_{3}\right)\right] \sin \left(N_{m_{2}} y\right) \sin \left[N_{n_{2}}\left(X-a_{X}\right)\right] d y d X\right. \\
& \left.-\int_{a_{X}}^{S_{X}+a_{X}} \int_{H_{3}}^{h} \sum_{n=1}^{N}\left[E_{n} \frac{\cosh \left[N_{n}(h-y)\right]}{\sinh \left[N_{n}\left(h-H_{3}\right)\right]} \sin \left[N_{n}\left(X-a_{X}\right)\right]\right] \sin \left(N_{m_{2}} y\right) \sin \left[N_{n_{2}}\left(X-a_{X}\right)\right] d y d X\right\} \text {. }
\end{aligned}
$$


Calling the first, second, third, fourth, fifth and sixth double integrals of Eq. A51 as $I^{(10)}, I^{(11)}, I^{(12)}, I^{(13)}, I^{(14)}$, and $I^{(15)}$, respectively, and simplifying these integrals, we have

$$
I^{(10)}=\sum_{q=1}^{Q}\left[C_{q} \frac{I_{a}^{(10)} I_{b}^{(10)}}{\cosh \left(N_{q} S_{X}\right)}\right],
$$

where for $\left(N_{q}\right)^{2}=\left(N_{m_{2}}\right)^{2}$

$$
I_{a}^{(10)}=\left(\frac{H_{3}}{2}\right)-\left[\frac{\sin \left(2 N_{q} H_{3}\right)}{4 N_{q}}\right]
$$

and for $\left(N_{q}\right)^{2} \neq\left(N_{m_{2}}\right)^{2}$

$$
I_{a}^{(10)}=\left\{\frac{\sin \left[\left(N_{q}-N_{m_{2}}\right) H_{3}\right]}{2\left(N_{q}-N_{m_{2}}\right)}\right\}-\left\{\frac{\sin \left[\left(N_{q}+N_{m_{2}}\right) H_{3}\right]}{2\left(N_{q}+N_{m_{2}}\right)}\right\}
$$

and

$$
\begin{aligned}
I_{b}^{(10)} & =\left[\frac{N_{n_{2}}}{\left(N_{q}\right)^{2}+\left(N_{n_{2}}\right)^{2}}\right] \cosh \left(N_{q} S_{X}\right) ; \\
I^{(11)} & =\sum_{p=1}^{P}\left[B_{p} \frac{I_{a}^{(11)} I_{b}^{(11)}}{\cosh \left(N_{p} H_{3}\right)}\right],
\end{aligned}
$$

where

$$
\begin{aligned}
I_{a}^{(11)} & =\left[\frac{N_{p}}{\left(N_{p}\right)^{2}+\left(N_{m_{2}}\right)^{2}}\right] \cosh \left(N_{p} H_{3}\right) \sin \left(N_{m_{2}} H_{3}\right) \\
& -\left[\frac{N_{m_{2}}}{\left(N_{p}\right)^{2}+\left(N_{m_{2}}\right)^{2}}\right] \sinh \left(N_{p} H_{3}\right) \cos \left(N_{m_{2}} H_{3}\right)
\end{aligned}
$$

and for $p=n_{2}$

$$
I_{b}^{(11)}=\frac{S_{X}}{2}
$$


and for $p \neq n_{2}$

$$
\begin{gathered}
I_{b}^{(11)}=0 ; \\
I^{(12)}=\sum_{m=1}^{M}\left[G_{m} \frac{I_{a}^{(12)} I_{b}^{(12)}}{\sinh \left(N_{m} H_{3}\right)}\right],
\end{gathered}
$$

where

$$
I_{a}^{(12)}=\left[\frac{N_{m_{2}}}{\left(N_{m}\right)^{2}+\left(N_{m_{2}}\right)^{2}}\right] \sinh \left(N_{m} H_{3}\right)-\left[\frac{N_{m}}{\left(N_{m}\right)^{2}+\left(N_{m_{2}}\right)^{2}}\right] \sin \left(N_{m_{2}} H_{3}\right)(\mathrm{A} 61)
$$

and for $m=n_{2}$

$$
I_{b}^{(12)}=\frac{S_{X}}{2}
$$

and for $m \neq n_{2}$

$$
\begin{gathered}
I_{b}^{(12)}=0 ; \\
I^{(13)}=H_{1}\left[\frac{\cos \left(N_{m_{2}} H_{3}\right)}{N_{m_{2}} N_{n_{2}}}\right] ; \\
I^{(14)}=\sum_{r=1}^{R}\left[D_{r} \frac{I_{a}^{(14)} I_{b}^{(14)}}{\cosh \left(N_{r} S_{X}\right)}\right],
\end{gathered}
$$

here for $\left(N_{r}\right)^{2}=\left(N_{m_{2}}\right)^{2}$

$$
I_{a}^{(14)}=\left[\left(\frac{h-H_{3}}{2}\right) \cos \left(-N_{r} H_{3}\right)\right]-\left\{\frac{\sin \left[\left(2 N_{r} h\right)-\left(N_{r} H_{3}\right)\right]-\sin \left(N_{r} H_{3}\right)}{4 N_{r}}\right\}
$$

and for $\left(N_{r}\right)^{2} \neq\left(N_{m_{2}}\right)^{2}$

$$
\begin{aligned}
I_{a}^{(14)}= & \left\{\frac{\sin \left[\left(N_{r}-N_{m_{2}}\right) h-\left(N_{r} H_{3}\right)\right]-\sin \left(-N_{m_{2}} H_{3}\right)}{2\left(N_{r}-N_{m_{2}}\right)}\right\} \\
& -\left\{\frac{\sin \left[\left(N_{r}+N_{m_{2}}\right) h-\left(N_{r} H_{3}\right)\right]-\sin \left(N_{m_{2}} H_{3}\right)}{2\left(N_{r}+N_{m_{2}}\right)}\right\},
\end{aligned}
$$

and 


$$
\begin{aligned}
& I_{b}^{(14)}=\left[\frac{N_{n_{2}}}{\left(N_{r}\right)^{2}+\left(N_{n_{2}}\right)^{2}}\right] \cosh \left(N_{r} S_{X}\right) ; \\
& I^{(15)}=\sum_{n=1}^{N}\left\{E_{n} \frac{I_{a}^{(15)} I_{b}^{(15)}}{\sinh \left[N_{n}\left(h-H_{3}\right)\right]}\right\},
\end{aligned}
$$

where

$$
\begin{aligned}
I_{a}^{(15)} & =\left[\frac{N_{m_{2}}}{\left(N_{n}\right)^{2}+\left(N_{m_{2}}\right)^{2}}\right] \cosh \left[N_{n}\left(h-H_{3}\right)\right] \cos \left(N_{m_{2}} H_{3}\right) \\
& +\left[\frac{N_{n}}{\left(N_{n}\right)^{2}+\left(N_{m_{2}}\right)^{2}}\right] \sinh \left[N_{n}\left(h-H_{3}\right)\right] \sin \left(N_{m_{2}} H_{3}\right),
\end{aligned}
$$

and for $n=n_{2}$

$$
I_{b}^{(15)}=\frac{S_{X}}{2}
$$

and for $n \neq n_{2}$,

$$
I_{b}^{(15)}=0
$$

Thus, from Eq. A51, $A_{m_{2} n_{2}}+\left(\sum_{m_{1}=1}^{M_{1}} \sum_{n_{1}=1}^{N_{1}} P_{m_{2} n_{2}}^{m_{1} n_{1}}\right)$ can be expressed as

$$
A_{m_{2} n_{2}}+\left(\sum_{m_{1}=1}^{M_{1}} \sum_{n_{1}=1}^{N_{1}} P_{m_{2} n_{2}}^{m_{1} n_{1}}\right)=\left(\frac{2}{S_{X}}\right)\left(\frac{2}{h}\right)\left[-I^{(10)}-I^{(11)}-I^{(12)}+I^{(13)}-I^{(14)}-I^{(15)}\right] .
$$

Now, applying conditions I to Eq. A36 and VII to Eq. 6, respectively, we get

$$
\begin{aligned}
& \sum_{w=1}^{W} F_{w} \frac{\cosh \left(N_{w} X\right)}{\cosh \left(N_{w} a_{X}\right)} \sin \left[N_{w}\left(y-H_{3}\right)\right] \\
&+ \sum_{m_{1}=1}^{M_{1}} \sum_{n_{1}=1}^{N_{1}} Z_{m_{1} n_{1}} \sin \left[N_{m_{1}}\left(y-H_{3}\right)\right] \cos \left(N_{n_{1}} X\right) \\
&+\sum_{m_{2}=1}^{M_{2}} \sum_{n_{2}=1}^{N_{2}} A_{m_{2} n_{2}} \sin \left(N_{m_{2}} y\right) \sin \left[N_{n_{2}}\left(X-a_{X}\right)\right]-H_{1}=0 \\
& \quad\left(0<X<a_{X}, \quad H_{3}<y<h\right)
\end{aligned}
$$


and

$$
\begin{aligned}
& \sum_{r=1}^{R} D_{r} \frac{\cosh \left[N_{r}\left(S_{X}+a_{X}-X\right)\right]}{\cosh \left(N_{r} S_{X}\right)} \sin \left[N_{r}\left(y-H_{3}\right)\right] \\
&+\sum_{n=1}^{N} E_{n} \frac{\cosh \left[N_{n}(h-y)\right]}{\sinh \left[N_{n}\left(h-H_{3}\right)\right]} \sin \left[N_{n}\left(X-a_{X}\right)\right] \\
&+\sum_{m_{1}=1}^{M_{1}} \sum_{n_{1}=1}^{N_{1}} Z_{m_{1} n_{1}} \sin \left[N_{m_{1}}\left(y-H_{3}\right)\right] \cos \left(N_{n_{1}} X\right) \\
&+\sum_{m_{2}=1}^{M_{2}} \sum_{n_{2}=1}^{N_{2}} A_{m_{2} n_{2}} \sin \left(N_{m_{2}} y\right) \sin \left[N_{n_{2}}\left(X-a_{X}\right)\right]-H_{1}=0, \\
& \quad\left(a_{X}<X<S_{X}+a_{X}, H_{3}<y<h\right) .
\end{aligned}
$$

Now, adjusting again the bases of the double summation terms of Eqs. A74 and A75, we get for each $m_{2}$ and $n_{2}$

$$
A_{m_{2} n_{2}} \sin \left(N_{m_{2}} y\right) \sin \left[N_{n_{2}}\left(X-a_{X}\right)\right]=\sum_{m_{1}=1}^{M_{1}} \sum_{n_{1}=1}^{N_{1}} U_{m_{1} m_{1}}^{m_{2} n_{2}} \sin \left[N_{m_{1}}\left(y-H_{3}\right)\right] \cos \left(N_{n_{1}} X\right) .
$$

Considering $M_{1} \rightarrow \infty$ and $N_{1} \rightarrow \infty$ in the above expression, $U_{m_{1} n_{1}}^{m_{2} n_{2}}$ can then be determined by performing a Fourier run on $0<X<S_{X}+a_{X}$, $H_{3}<y<h$; thus, we have

$$
\begin{aligned}
& U_{m_{1} n_{1}}^{m_{2} n_{2}}=\left(\frac{2}{S_{X}+a_{X}}\right)\left(\frac{2}{h-H_{3}}\right)\left\{\int_{H_{3}}^{h} \int_{0}^{a_{X}}(0) \times \sin \left[N_{m_{1}}\left(y-H_{3}\right)\right] \cos \left(N_{n_{1}} X\right) d X d y\right. \\
& \left.+\int_{H_{3}}^{h} \int_{a_{X}}^{S_{X}+a_{X}} A_{m_{2} n_{2}} \sin \left(N_{m_{2}} y\right) \sin \left[N_{n_{2}}\left(X-a_{X}\right)\right] \sin \left[N_{m_{1}}\left(y-H_{3}\right)\right] \cos \left(N_{n_{1}} X\right) d X d y\right\} .
\end{aligned}
$$

Simplifying the above integrals, we get

$$
U_{m_{1} n_{1}}^{m_{2} n_{2}}=\left(\frac{2}{S_{X}+a_{X}}\right)\left(\frac{2}{h-H_{3}}\right)\left[A_{m_{2} n_{2}} I_{a}^{(16)} I_{b}^{(16)}\right],
$$

where for $\left(N_{m_{1}}\right)^{2}=\left(N_{m_{2}}\right)^{2}$

$$
I_{a}^{(16)}=\left[\left(\frac{h-H_{3}}{2}\right) \cos \left(N_{m_{1}} H_{3}\right)\right]-\left\{\frac{\sin \left[\left(2 N_{m_{2}} h\right)-\left(N_{m_{1}} H_{3}\right)\right]-\sin \left[\left(2 N_{m_{2}} H_{3}\right)-\left(N_{m_{1}} H_{3}\right)\right]}{4 N_{m_{2}}}\right\}
$$


and for $\left(N_{m_{1}}\right)^{2} \neq\left(N_{m_{2}}\right)^{2}$

$$
\begin{aligned}
I_{a}^{(16)}= & \left\{\frac{\sin \left[\left(N_{m_{2}}-N_{m_{1}}\right) h+\left(N_{m_{1}} H_{3}\right)\right]-\sin \left(N_{m_{2}} H_{3}\right)}{2\left(N_{m_{2}}-N_{m_{1}}\right)}\right\} \\
& -\left\{\frac{\sin \left[\left(N_{m_{2}}+N_{m_{1}}\right) h-\left(N_{m_{1}} H_{3}\right)\right]-\sin \left(N_{m_{2}} H_{3}\right)}{2\left(N_{m_{2}}+N_{m_{1}}\right)}\right\},
\end{aligned}
$$

for $\left(N_{n_{1}}\right)^{2}=\left(N_{n_{2}}\right)^{2}$

$$
I_{b}^{(16)}=\left[\left(\frac{S_{X}}{2}\right) \sin \left(-N_{n_{2}} a_{X}\right)\right]-\left\{\frac{\cos \left[\left(2 N_{n_{2}}\right)\left(S_{X}+a_{X}\right)-\left(N_{n_{2}} a_{X}\right)\right]-\cos \left(N_{n_{2}} a_{X}\right)}{4 N_{n_{2}}}\right\}
$$

and for $\left(N_{n_{1}}\right)^{2} \neq\left(N_{n_{2}}\right)^{2}$

$$
\begin{aligned}
I_{b}^{(16)} & =-\left\{\frac{\cos \left[\left(N_{n_{2}}-N_{n_{1}}\right)\left(S_{X}+a_{X}\right)-\left(N_{n_{2}} a_{X}\right)\right]-\cos \left(-N_{n_{1}} a_{X}\right)}{2\left(N_{n_{2}}-N_{n_{1}}\right)}\right\} \\
& -\left\{\frac{\cos \left[\left(N_{n_{2}}+N_{n_{1}}\right)\left(S_{X}+a_{X}\right)-\left(N_{n_{2}} a_{X}\right)\right]-\cos \left(N_{n_{1}} a_{X}\right)}{2\left(N_{n_{2}}+N_{n_{1}}\right)}\right\} .
\end{aligned}
$$

Substituting Eq. A76 in Eqs. A74 and A75, respectively, we obtain

$$
\begin{gathered}
\sum_{m_{1}=1}^{M_{1}} \sum_{n_{1}=1}^{N_{1}}\left[Z_{m_{1} n_{1}}+\left(\sum_{m_{2}=1}^{M_{2}} \sum_{n_{2}=1}^{N_{2}} U_{m_{1} n_{1}}^{m_{2} n_{2}}\right)\right] \sin \left[N_{m_{1}}\left(y-H_{3}\right)\right] \cos \left(N_{n_{1}} X\right)=H_{1} \\
-\sum_{w=1}^{W} F_{w} \frac{\cosh \left(N_{w} X\right)}{\cosh \left(N_{w} a_{X}\right)} \sin \left[N_{w}\left(y-H_{3}\right)\right], \\
\left(0<X<a_{X}, H_{3}<y<h\right)
\end{gathered}
$$

and 


$$
\begin{gathered}
\sum_{m_{1}=1}^{M_{1}} \sum_{n_{1}=1}^{N_{1}}\left[Z_{m_{1} n_{1}}+\left(\sum_{m_{2}=1}^{M_{2}} \sum_{n_{2}=1}^{N_{2}} U_{m_{1} n_{1}}^{m_{2} n_{2}}\right)\right] \sin \left[N_{m_{1}}\left(y-H_{3}\right)\right] \cos \left(N_{n_{1}} X\right)=H_{1} \\
-\sum_{r=1}^{R} D_{r} \frac{\cosh \left[N_{r}\left(S_{X}+a_{X}-X\right)\right]}{\cosh \left(N_{r} S_{X}\right)} \sin \left[N_{r}\left(y-H_{3}\right)\right] \\
-\sum_{n=1}^{N} E_{n} \frac{\cosh \left[N_{n}(h-y)\right]}{\sinh \left[N_{n}\left(h-H_{3}\right)\right]} \sin \left[N_{n}\left(X-a_{X}\right)\right] \\
\left(a_{X}<X<S_{X}+a_{X}, H_{3}<y<h\right) .
\end{gathered}
$$

Thus, letting $M_{1} \rightarrow \infty$ and $N_{1} \rightarrow \infty$ in Eqs. A83 and A84, a Fourier run can be executed in $0<X<a_{X}+S_{X}, H_{3}<y<h$; this yields an expression for $Z_{m_{1} n_{1}}+\left(\sum_{m_{2}=1}^{M_{2}} \sum_{n_{2}=1}^{N_{2}} U_{m_{1} n_{1}}^{m_{2} n_{2}}\right)$ as

$$
\begin{aligned}
& Z_{m_{1} n_{1}}+\left(\sum_{m_{2}=1}^{M_{2}} \sum_{n_{2}=1}^{N_{2}} U_{m_{1} n_{1}}^{m_{2} n_{1}}\right)=\left(\frac{2}{S_{X}+a_{X}}\right)\left(\frac{2}{h-H_{3}}\right)\left\{\int_{H_{3}}^{h} \int_{0}^{S_{X}+a_{X}} H_{1} \sin \left[N_{m_{1}}\left(y-H_{3}\right)\right] \cos \left(N_{n_{1}} X\right) d X d y\right. \\
& -\int_{H_{3}}^{h} \int_{0}^{a_{X}} \sum_{w=1}^{W}\left[F_{w} \frac{\cosh \left(N_{w} X\right)}{\cosh \left(N_{w} a_{X}\right)} \sin \left[N_{w}\left(y-H_{3}\right)\right]\right] \sin \left[N_{m_{1}}\left(y-H_{3}\right)\right] \cos \left(N_{n_{1}} X\right) d X d y \\
& -\int_{H_{3}}^{h} \int_{a_{X}}^{S_{X}+a_{X}} \sum_{r=1}^{R}\left[D_{r} \frac{\cosh \left[N_{r}\left(S_{X}+a_{X}-X\right)\right]}{\cosh \left(N_{r} S_{X}\right)} \sin \left[N_{r}\left(y-H_{3}\right)\right] \sin \left[N_{m_{1}}\left(y-H_{3}\right)\right] \cos \left(N_{n_{1}} X\right) d X d y\right. \\
& \left.-\int_{H_{3}}^{h} \int_{a_{X}}^{S_{X}+a_{X}} \sum_{n=1}^{N}\left[E_{n} \frac{\cosh \left[N_{n}(h-y)\right]}{\sinh \left[N_{n}\left(h-H_{3}\right)\right]} \sin \left[N_{n}\left(X-a_{X}\right)\right]\right] \sin \left[N_{m_{1}}\left(y-H_{3}\right)\right] \cos \left(N_{n_{1}} X\right) d X d y\right\} .
\end{aligned}
$$

Identifying the first, second, third, and the fourth integrals as $I^{(17)}, I^{(18)}$, $I^{(19)}$, and $I^{(20)}$, respectively, and solving these integrals, we have

$$
\begin{gathered}
I^{(17)}=0 \\
I^{(18)}=\sum_{w=1}^{W}\left[F_{w} \frac{I_{a}^{(18)} I_{b}^{(18)}}{\cosh \left(N_{w} a_{X}\right)}\right],
\end{gathered}
$$

where for $w=m_{1}$

$$
I_{a}^{(18)}=\left(\frac{h-H_{3}}{2}\right),
$$

and for $w \neq m_{1}$ 


$$
I_{a}^{(18)}=0
$$

and

$$
\begin{gathered}
I_{b}^{(18)}=\left\{\left[\frac{N_{n_{1}}}{\left(N_{n_{1}}\right)^{2}+\left(N_{w}\right)^{2}}\right] \cosh \left(N_{w} a_{X}\right) \sin \left(N_{n_{1}} a_{X}\right)\right\} \\
+\left\{\left[\frac{N_{w}}{\left(N_{n_{1}}\right)^{2}+\left(N_{w}\right)^{2}}\right] \sinh \left(N_{w} a_{X}\right) \cos \left(N_{n_{1}} a_{X}\right)\right\} ; \\
I^{(19)}=\sum_{r=1}^{R}\left[D_{r} \frac{I_{a}^{(19)} I_{b}^{(19)}}{\cosh \left(N_{r} S_{X}\right)}\right],
\end{gathered}
$$

where for $r=m_{1}$

$$
I_{a}^{(19)}=\left(\frac{h-H_{3}}{2}\right) \text {, }
$$

and for $r \neq m_{1}$

$$
I_{a}^{(19)}=0
$$

and

$$
\begin{aligned}
I_{b}^{(19)} & =\left\{\left[\frac{N_{r}}{\left(N_{n_{1}}\right)^{2}+\left(N_{r}\right)^{2}}\right] \sinh \left(N_{r} S_{X}\right) \cos \left(N_{n_{1}} a_{X}\right)\right\} \\
& -\left\{\left[\frac{N_{n_{1}}}{\left(N_{n_{1}}\right)^{2}+\left(N_{r}\right)^{2}}\right] \cosh \left(N_{r} S_{X}\right) \sin \left(N_{n_{1}} a_{X}\right)\right\} ; \\
I^{(20)} & =\sum_{n=1}^{N}\left\{E_{n} \frac{I_{a}^{(20)} I_{b}^{(20)}}{\sinh \left[N_{n}\left(h-H_{3}\right)\right]}\right\},
\end{aligned}
$$

where

$$
I_{a}^{(20)}=\left[\frac{N_{m_{1}}}{\left(N_{m_{1}}\right)^{2}+\left(N_{n}\right)^{2}}\right] \cosh \left[N_{n}\left(h-H_{3}\right)\right],
$$


and for $\left(N_{n_{1}}\right)^{2}=\left(N_{n}\right)^{2}$

$$
I_{b}^{(20)}=\left[\left(\frac{S_{X}}{2}\right) \sin \left(-N_{n} a_{X}\right)\right]-\left\{\frac{\cos \left[\left(2 N_{n}\right)\left(S_{X}+a_{X}\right)-\left(N_{n} a_{X}\right)\right]-\cos \left(N_{n} a_{X}\right)}{4 N_{n}}\right\}
$$

and for $\left(N_{n_{1}}\right)^{2} \neq\left(N_{n}\right)^{2}$

$$
\begin{aligned}
I_{b}^{(20)} & =-\left\{\frac{\cos \left[\left(N_{n}-N_{n_{1}}\right)\left(S_{X}+a_{X}\right)-\left(N_{n} a_{X}\right)\right]-\cos \left(-N_{n_{1}} a_{X}\right)}{2\left(N_{n}-N_{n_{1}}\right)}\right\} \\
& -\left\{\frac{\cos \left[\left(N_{n}+N_{n_{1}}\right)\left(S_{X}+a_{X}\right)-\left(N_{n} a_{X}\right)\right]-\cos \left(N_{n_{1}} a_{X}\right)}{2\left(N_{n}+N_{n_{1}}\right)}\right\} .
\end{aligned}
$$

Thus, from Eq. A85, $Z_{m_{1} n_{1}}+\left(\sum_{m_{2}=1}^{M_{2}} \sum_{n_{2}=1}^{N_{2}} U_{m_{1} n_{1}}^{m_{2} n_{2}}\right)$ can be expressed as

$$
Z_{m_{1} n_{1}}+\left(\sum_{m_{2}=1}^{M_{2}} \sum_{n_{2}=1}^{N_{2}} U_{m_{1} n_{1}}^{m_{2} n_{2}}\right)=\left(\frac{2}{S_{X}+a_{X}}\right)\left(\frac{2}{h-H_{3}}\right)\left[I^{(17)}-I^{(18)}-I^{(19)}-I^{(20)}\right] .
$$

Now, Eqs. A73 and A99 can be utilized to work out the necessary linear equations to evaluate the required double Fourier coefficients $Z_{m_{1} n_{1}}$ and $A_{m_{2} n_{2}}$ by considering suitable integral values of $M_{1}, N_{1}, M_{2}$, and $N_{2}$. In all the drainage problems studied here, we have taken $M_{1}=N_{1}=M_{2}=N_{2}$ while carrying out the computations. It should be noted that $P_{m_{2} n_{2}}^{m_{1} n_{1}}$ of Eq. A73 is being linked with $Z_{m_{1} n_{1}}$ through Eq. A47 and that $U_{m_{1} n_{1}}^{m_{2} n_{2}}$ of the above equation is being linked with $A_{m_{2} n_{2}}$ through Eq. A78. Once the linear equations corresponding to a flow situation are in place, they can then be solved by resorting to a suitable iterative procedure (Saad 2003) to evaluate these constants. We have thus evaluated all the unknown coefficients associated with the hydraulic heads function of Eqs. 5-7 and hence our boundary value problem stands solved. 


\section{References}

Abrol, I.P., J.S.P. Yadav, and F.I. Massoud (1988), Salt-affected Soils and Their Management, FAO Soils Bulletin, Vol. 39, Food and Agriculture Organization of the United Nations, Rome, $131 \mathrm{pp}$.

Barua, G., and W. Alam (2013), An analytical solution for predicting transient seepage into ditch drains from a ponded field, Adv. Water Resour. 52, 78-92, DOI: 10.1016/j.advwatres.2012.09.002.

Barua, G., and K.N. Tiwari (1995), Analytical solutions of seepage into ditches from ponded fields, J. Irrig. Drain. Eng. 121, 6, 396-404, DOI: 10.1061/(ASCE) 0733-9437(1995)121:6(396).

Bear, J. (1972), Dynamics of Fluids in Porous Media, Elsevier, New York.

Bereslavskii, E.N. (2006), Groundwater flow to a system of drainage canals, Water Resour. 33, 4, 417-420, DOI: 10.1134/S0097807806040075.

Bradbury, R.B., and W.B. Kirby (2006), Farmland birds and resource protection in the UK: Cross-cutting solutions for multi-functional farming?, Biol. Conserv. 129, 4, 530-542, DOI: 10.1016/j.biocon.2005.11.020.

Chahar, B.R., and G.P. Vadodaria (2008a), Steady subsurface drainage of homogeneous soils by ditches, Proc. ICE Water Manage. 161, 6, 303-11, DOI: 10.1680/wama.2008.161.6.303.

Chahar, B.R., and G.P. Vadodaria (2008b), Drainage of ponded surface by an array of ditches, J. Irrig. Drain. Eng. 134, 6, 815-823, DOI: 10.1061/(ASCE) 0733-9437(2008)134:6(815).

Chahar, B.R., and G.P. Vadodaria (2012), Steady subsurface drainage of ponded surface by an array of parallel ditches, J. Hydrol. Eng. ASCE 17, 8, 895908, DOI: 10.1061/(ASCE)HE.1943-5584.0000518.

Chen, C.-S., and C.-C. Chang (2003), Well hydraulics theory and data analysis of the constant head test in an unconfined aquifer with the skin effect, Water Resour. Res. 39, 5, 1121, DOI: 10.1029/2002WR001516.

Chen, S.K., C.W. Liu, and H.C. Huang (2002), Analysis of water movement in paddy rice fields (II) simulation studies, J. Hydrol. 268, 1-4, 259-271, DOI: 10.1016/S0022-1694(02)00180-4.

Chiang, W.H., and W. Kinzelbach (2001), 3D-Groundwater Modeling with PMWIN: A Simulation System for Modeling Groundwater Flow and Pollution, 3rd ed., Springer, Berlin Heidelberg, DOI: 10.1007/978-3-662-05549-6.

Darzi-Naftchali, A., S.M. Mirlatifi, A. Shahnazari, F. Ejlali, and M.H. Mahdian (2013), Effect of subsurface drainage on water balance and water table in poorly drained paddy fields, Agr. Water Manage. 130, 61-68, DOI: 10.1016/j.agwat.2013.08.017.

Datta, K.K., and C. de Jong (2002), Adverse effect of waterlogging and soil salinity on crop and land productivity in northwest region of Haryana, India, Agr. Water Manage. 57, 3, 223-238, DOI: 10.1016/S0378-3774(02)00058-6. 
Datta, K.K., C. de Jong, and O.P. Singh (2000), Reclaiming salt-affected land through drainage in Haryana, India: a financial analysis, Agr. Water Manage. 46, 1, 55-71, DOI: 10.1016/S0378-3774(00)00077-9.

Dieleman, P.J. (ed.) (1973), Reclamation of Salt Affected Soils in Iraq, Soil Hydrological and Agricultural Studies, Publ. no. 11, International Institute for Land Reclamation and Improvement, Wageningen, The Netherlands.

Elfeki, A.M.M., G.J.M. Uffink, and F.B.J. Barends (1997), Goundwater Contaminnant Transport: Impact of Heterogeneous Characterization: A New View on Dispersion, A.A. Balkema, Rotterdam, 312 pp.

FAO (2002), World Food Summit - five years later, Food and Agriculture Organization of the United Nations, 10-13 June 2002, Rome, Italy, http://www.fao. org/worldfoodsummit/english/newsroom/focus/focus1.htm.

Fukuda, H. (1957), Underdrainage into ditches in soil overlying an impervious substratum, EOS Trans. Am. Geophys. Union 38, 5, 730-739, DOI: 10.1029/ TR038i005p00730.

Ghassemi, F., A.J. Jakeman, and H.A. Nix (1995), Salinisation of Land and Water Resource: Human Causes, Extent, Management and Case Studies, CABI Publishing Series, CAB International Publ., Wallingford, 526 pp.

Grisak, G.E., and J.A. Cherry (1975), Hydrologic characteristics and response of fractured till and clay confining a shallow aquifer, Can. Geotech. J. 12, 1, 23-43, DOI: 10.1139/t75-003.

Grove, D.B., W.A. Beetem, and F.B. Sower (1970), Fluid travel time between a recharging well pair in an aquifer having a uniform regional flow field, Water Resour. Res. 6, 5, 1404-1410, DOI: 10.1029/WR006i005p01404.

Haitjema, H. (2006), The role of hand calculations in ground water flow modeling, Ground Water 44, 6, 786-791, DOI: 10.1111/j.1745-6584.2006.00189.x.

Hendry, M.J. (1982), Hydraulic conductivity of a glacial till in Alberta, Ground Water 20, 2, 162-169, DOI: 10.1111/j.1745-6584.1982.tb02744.x.

Ilyinsky, N.B., and A.R. Kacimov (1992), Problems of seepage to empty ditch and drain, Water Resour. Res. 28, 3, 871-877, DOI: 10.1029/91WR02662.

Jones, L., T. Lemar, and C.-T. Tsai (1992), Results of two pumping tests in Wisconsin age weathered till in Iowa, Ground Water 30, 4, 529-538, DOI: 10.1111/j.1745-6584.1992.tb01529.x.

Kacimov, A.R. (1997), Dynamics of groundwater mounds: analytical solutions and integral characteristics, Hydrol. Sci. J. 42, 3, 329-342, DOI: 10.1080/ 02626669709492032.

Kirkham, D. (1945), Artificial drainage of land: Streamline experiments. The Artesian basin - III, EOS Trans. Am. Geophys. Union 26, 3, 393-406, DOI: 10.1029/TR026i003p00393.

Kirkham, D. (1949), Flow of ponded water into drain tubes in soil overlying an impervious layer, EOS Trans. Am. Geophys. Union 30, 3, 369-385, DOI: 10.1029/TR030i003p00369. 
Kirkham, D. (1950), Seepage into ditches in the case of a plane water table and an impervious substratum, EOS Trans. Am. Geophys. Union 31, 3, 425-430, DOI: 10.1029/TR031i003p00425.

Kirkham, D. (1960), Seepage into ditches from a plane water table overlying a gravel substratum, J. Geophys. Res. 65, 4, 1267-1272, DOI: 10.1029/ JZ065i004p01267.

Kirkham, D. (1965), Seepage of leaching water into drainage ditches of unequal water level heights, J. Hydrol. 3, 3-4, 207-224, DOI: 10.1016/0022-1694(65) 90081-8.

Kirkham, D., and W.L. Powers (1972), Advanced Soil Physics, John Wiley \& Sons Inc., New York.

Kirkham, D., S. Toksöz, and R.R. van der Ploeg (1974), Steady flow to drains and wells. In: J. van Schilfgaarde, Drainage for Agriculture, Agronomy Monograph Series, American Society of Agronomy Inc., 203-244.

MacDonald, A.M. L. Maurice, M.R. Dobbs, H.J. Reeves, and C.A. Auton (2012), Relating in situ hydraulic conductivity, particle size and relative density of superficial deposits in a heterogeneous catchment, J. Hydrol. 434-435, 130141, DOI: 10.1016/j.jhydrol.2012.01.018.

Manjunatha, M.V., R.J. Oosterbaan, S.K. Gupta, H. Rajkumar, and H. Jansen (2004), Performance of subsurface drains for reclaiming waterlogged saline lands under rolling topography in Tungabhadra irrigation project in India, Agr. Water Manage. 69, 1, 69-82, DOI: 10.1016/j.agwat.2004.01.001.

Marja, R. (2013), The relationships between farmland birds, land use and landscape structure in Northern Europe, Ph.D. Thesis, University of Tartu Press, Tartu, Estonia.

Marja, R., and I. Herzon (2012), The importance of drainage ditches for farmland birds in agricultural landscapes in the Baltic countries: does field type matter?, Ornis Fennica 89, 3, 170-181.

Martinez-Beltran, J. (1978), Drainage and reclamation of salt-affected soils in the Bardenas area, Spain, Ph.D. Thesis, ILRI Publication 24, International Institute for Land Reclamation and Improvement, Wageningen, The Netherlands.

Mirjat, M.S., and D.A. Rose (2009), Streamline pattern and salt leaching through progressive flooding between subsurface drains, Irrig. Drain. 58, 2, 199208, DOI: 10.1002/ird.398.

Needelman, B.A., P.J.A. Kleinman, J.S. Strock, and A.L. Allen (2007), Improved management of agricultural drainage ditches for water quality protection: An overview, J. Soil Water Conserv. 62, 4, 171-178.

Neuman, S.P. (1975), Analysis of pumping test data from anisotropic unconfined aquifers considering delayed gravity response, Water Resour. Res. 11, 2, 329-342, DOI: 10.1029/WR011i002p00329. 
Ogino, Y., and K. Murashima (1993), Subsurface drainage system of large size paddies for crop diversification in Japan. In: 15th Int. Congress on Irrigation and Drainage "Water Management in the Next Century", 4-11 September 1993, Hague, The Netherlands.

Praveena, S.M., M.H. Abdullah, A.Z. Aris, and K. Bidin (2010), Groundwater solution techniques: Environmental applications, J. Water Resour. Protec. 2, 1, 8-13, DOI: $10.4236 /$ jwarp.2010.21002.

Qiu, J. (2009), China cuts methane emissions from rice fields, Nature News, $18 \mathrm{Au}-$ gust 2009, DOI: 10.1038/news.2009.833.

Rao, K.V.G.K., and P.B. Leeds-Harrison (1991), Desalination with subsurface drainage, Agr. Water Manage. 19, 4 303-311, DOI: 10.1016/0378-3774(91) 90023-C.

Rhoades, J.D. (1997), Sustainability of irrigation: An overview of salinity problems and control strategies. In: Proc. Ann. Conf. Canadian Water Resources Association "Footprints of Humanity: Reflections on Fifty Years of Water Resources Developments", 3-6 June 1997, Lethbridge, Alberta, Canada.

Ritzema, H.P., T.V. Satyanarayana, S. Raman, and J. Boonstra (2008), Subsurface drainage to combat water logging and salinity in irrigated lands in India: Lessons learned in farmer's fields, Agr. Water Manage. 95, 3, 179-189, DOI: 10.1016/j.agwat.2007.09.012.

Römkens, M.J.M. (2009), Estimating seepage and hydraulic potentials near incised ditches in a homogeneous, isotropic aquifer, Earth Surf. Process. Landforms 34, 14, 1903-1914, DOI: 10.1002/esp.1880.

Römkens, M.J.M. (2010), Erosion and sedimentation research in agricultural watersheds in the USA: From past to present and beyond. In: IAHS-AISH Publication 337, 17-26.

Saad, Y. (2003), Iterative Methods for Sparse Linear Systems, 2nd ed., Society for Industrial and Applied Mathematics, Philadelphia.

Scarborough, J.B. (1966), Numerical Mathematical Analysis, 6th ed., Oxford and IBH Publ. Co., New Delhi, 203-207.

Sharma, D.P., and S.K. Gupta (2006), Subsurface drainage for reversing degradation of waterlogged saline lands, Land Degrad. Dev. 17, 6, 605-614, DOI: 10.1002/1dr.737.

Sharp, J.M. Jr. (1984), Hydrogeologic characteristics of shallow glacial drift aquifers in dissected till plains (north-central Missouri), Ground Water 22, 6, 683689, DOI: 10.1111/j.1745-6584.1984.tb01436.x.

Shaver, R.B. (1998), The determination of glacial till specific storage in North Dakota, Ground Water 36, 4, 552-557, DOI: 10.1111/j.1745-6584.1998. tb02828.x.

Shiratori, Y., H. Watanabe, Y. Furukawa, H. Tsuruta, and K. Inubushi (2007), Effectiveness of a subsurface drainage system in poorly drained paddy fields on 
reduction of methane emissions, Soil Sci. Plant Nutr. 53, 4, 387-400, DOI: 10.1111/j.1747-0765.2007.00171.x.

Singh, J., and J.P. Singh (1995), Land degradation and economic sustainability, Ecol. Econ. 15, 1, 77-86, DOI: 10.1016/0921-8009(95)00037-A.

Stibinger, J. (2009), Terrain experimental measurement of saturated hydraulic conductivity on paddy fields in Taoyuan (Taiwan) during the cycle of flooded period, Agr. Trop. Subtrop. 42, 2, 82-89.

Szilagyi, J. (2003), Sensitivity analysis of aquifer parameter estimations based on the Laplace equation with linearized boundary conditions, Water Resour. Res. 39, 6, 1156, DOI: 10.1029/2002WR001564.

Tabuchi, T. (2004), Improvement of paddy field drainage for mechanization, Paddy Water Environ. 2, 1, 5-10, DOI: 10.1007/s10333-004-0034-7.

Warrick, A.W., and D. Kirkham (1969), Two-dimensional seepage of ponded water to full ditch drains, Water Resour. Res. 5, 3, 685-693, DOI: 10.1029/ WR005i003p00685.

Youngs, E.G. (1994), Seepage to ditches from a ponded surface, J. Hydrol. 161, 1-4, 145-154, DOI: 10.1016/0022-1694(94)90125-2.

Youngs, E.G., and P.B. Leeds-Harrison (2000), Improving efficiency of desalinization with subsurface drainage, J. Irrig. Drain. Eng. 126, 6, 375-380, DOI: 10.1061/(ASCE)0733-9437(2000)126:6(375).

Zhang, W., Y. Yu, Y. Huang, T. Li, and P. Wang (2011), Modeling methane emissions from irrigated rice cultivation in China from 1960 to 2050, Global Change Biol. 17, 12, 3511-3523, DOI: 10.1111/j.1365-2486.2011.02495.x.

Zhao, X., J. He, and J. Cao (2011), Study on mitigation strategies of methane emission from rice paddies in the implementation of ecological agriculture, Energy Procedia 5, 2474-2480, DOI: 10.1016/j.egypro.2011.03.425.

Received 11 June 2014

Received in revised form 21 November 2014 Accepted 28 January 2015 